OPEN ACCESS

Edited by: Anirban Bhunia,

Bose Institute, India

Reviewed by:

Rajeev K. Singla

Sichuan University, China

Biswajit Mishra,

Brown University, United States

Rathi Saravanan,

Nanyang Technological University,

Singapore

${ }^{*}$ Correspondence:

Sanhita Roy

sanhita@/vpei.org

Specialty section:

This article was submitted to

Medicinal and Pharmaceutical

Chemistry,

a section of the journal

Frontiers in Chemistry

Received: 19 April 2021

Accepted: 02 July 2021

Published: 11 August 2021

Citation:

Jadi PK, Sharma $P$, Bhogapurapu $B$ and Roy $S$ (2021) Alternative

Therapeutic Interventions:

Antimicrobial Peptides and Small

Molecules to Treat Microbial Keratitis.

Front. Chem. 9:694998.

doi: 10.3389/fchem.2021.694998

\section{Alternative Therapeutic Interventions: Antimicrobial Peptides and Small Molecules to Treat Microbial Keratitis}

\author{
Praveen Kumar Jadi ${ }^{1}$, Prerana Sharma ${ }^{1,2}$, Bharathi Bhogapurapu ${ }^{1}$ and Sanhita Roy ${ }^{1 *}$ \\ ${ }^{1}$ Prof, Brien Holden Eye Research Centre, LV Prasad Eye Institute, Hyderabad, India, ${ }^{2}$ Department of Animal Sciences, University \\ of Hyderabad, Hyderabad, India
}

Microbial keratitis is a leading cause of blindness worldwide and results in unilateral vision loss in an estimated 2 million people per year. Bacteria and fungus are two main etiological agents that cause corneal ulcers. Although antibiotics and antifungals are commonly used to treat corneal infections, a clear trend with increasing resistance to these antimicrobials is emerging at rapid pace. Extensive research has been carried out to determine alternative therapeutic interventions, and antimicrobial peptides (AMPs) are increasingly recognized for their clinical potential in treating infections. Small molecules targeted against virulence factors of the pathogens and natural compounds are also explored to meet the challenges and growing demand for therapeutic agents. Here we review the potential of AMPs, small molecules, and natural compounds as alternative therapeutic interventions for the treatment of corneal infections to combat antimicrobial resistance. Additionally, we have also discussed about the different formats of drug delivery systems for optimal administration of drugs to treat microbial keratitis.

Keywords: ocular surface, wound healing, microbial keratitis, antimicrobial pepides, small molecules, drug delivery systems

\section{INTRODUCTION}

Microbial keratitis is a leading cause of blindness in India and globally and is a major public health issue that compromises the quality of life. The early symptoms include redness, extreme pain, light sensitivity, and reduced vision. According to the World Health Organization (WHO), corneal infections are likely to cause 1.5-2 million new cases of blindness per year (Whitcher et al., 2001). The risk factors include ocular trauma and injuries, commonly caused by vegetative matters in the developing world. A study found that almost $70 \%$ of microbial keratitis cases in South India resulted from ocular trauma and $63 \%$ of all patients were involved in agriculture (Bharathi et al., 2007). Alternatively, the increased use of contact lens and self-diagnosed use of corticosteroids in the modern urban livelihood are the contributing risk factors in the developed world. Studies conducted in France and Sweden showed contact lens wear as a major risk factor in 50\% of all keratitis cases (Sagerfors et al., 2020). Bacterial and fungal infections constitute two major forms of corneal infections, consisting of 60 and 39\%, respectively (Das et al., 2019). The most common bacterial species responsible for causing corneal infections are Pseudomonas aeruginosa and Streptococcus spp. along with Staphylococcus aureus, S. epidermidis, Serratia marcescens, and Haemophilus influenza (Bremond-Gignac et al., 2011; Paradiso et al., 2016; Chojnacki et al., 2019; Urwin et al., 2020). In contrast to bacterial keratitis, fungal keratitis occurs widely in the tropical and subtropical climates, and Aspergillus spp. and Fusarium spp. are the most common etiological agents. Fungal infections of 


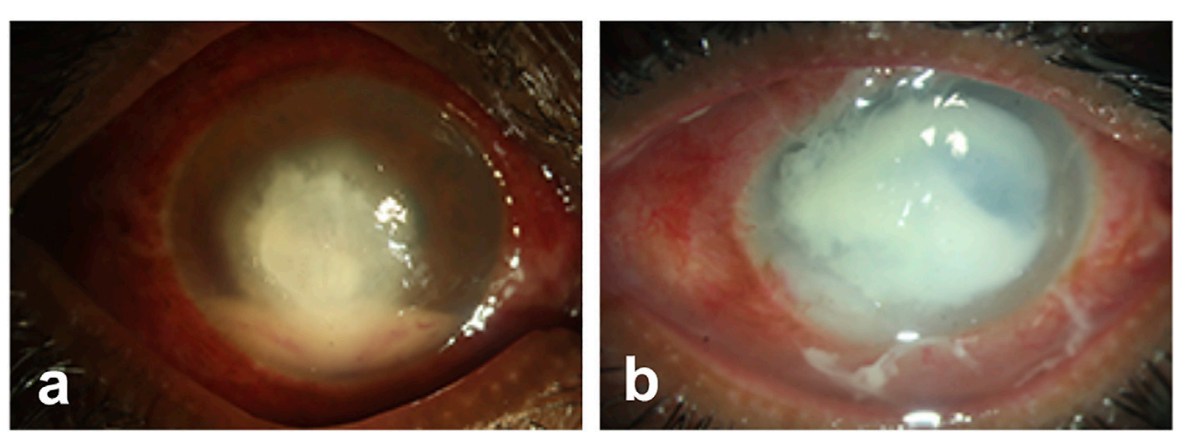

FIGURE 1 | Representative images of microbial keratitis. The pathogens causing infections penetrates deep into the stroma inducing inflammation and corneal opacity that leads to loss of vision.

the cornea need to be promptly recognized to facilitate a complete recovery as it is often difficult to treat due to penetration of the hyphae into the stroma. Infection with Fusarium spp. often completely destroy an eye in a few weeks, since the infection is usually severe, and perforation may supervene (Thomas, 2003). Studies have shown that almost $42-60 \%$ of corneal infections due to Aspergillus spp. lead to penetrating keratoplasty (Leck et al., 2002).

The representative image of corneal infections caused by $A$. flavus (Figure 1A) and $P$. aeruginosa (Figure 1B) shows increased inflammation and corneal opacity associated with microbial keratitis. Bacterial infections are commonly treated by topical, or subconjunctival administration with penicillin, fluoroquinolones, tetracyclines, and aminoglycosides (Sharma, 2011; Dubald et al., 2018). However, bacteria are gaining resistance against available antibiotics due to the misuse or prophylactic use of antibiotics as well as adaptation of bacteria to the available therapeutics. Similarly, a parallel rise in the number of drug-resistant fungal species is also reported lately. Therefore, researchers are trying to develop new therapeutics or exploring the natural compound to inhibit microbial infections and combat antimicrobial resistance (AMR).

In this review, we have discussed the important role of antimicrobial peptides (AMPs), natural compounds, and small molecules in combating corneal infections. Additionally, we have explored the importance of drug delivery systems in delivering the therapeutics for the treatment of microbial keratitis.

\section{METHODS}

We used online literature databases like PubMed and Scopus for searching relevant research articles based on the specific keywords. The keywords used for search included "keratitis", "antimicrobial resistance", "antimicrobial peptides", "small molecules", "drug delivery systems for delivering antimicrobial drugs," and "wound healing". The results were narrowed down by selecting articles relevant to the current review. The Food and Drug Administration (FDA) website was searched for the list of approved antimicrobial peptides in clinical use.

\section{ANTIMICROBIAL RESISTANCE AND LIMITATIONS OF ANTIMICROBIAL DRUGS}

Currently, ocular infections due to bacteria are managed using antibiotics like fluoroquinolones, vancomycin, cefazoline, bacitracin, sulfamethoxazole, erythromycin, chloramphenicol, and aminoglycosides (Lin et al., 2019). However, ever since the discovery of the first antibiotic penicillin, bacteria have shown to develop resistance against them in no time (Fairbrother, 1956). The Antibiotic Resistance Monitoring in Ocular Microorganisms (ARMOR) surveillance program, in its recent antibiotic resistance reports on 4,829 isolates, showed that $S$. aureus strains, including methicillin-resistant $S$. aureus (MRSA), are resistant to moxifloxacin (Thomas et al., 2019). In a recent report it was found that isolates of $S$. aureus and $S$. pneumoniae causing infectious keratitis show reduced susceptibility to fluoroquinolones (Sagerfors et al., 2020). Other reports found that Corynebacterium spp. present on the ocular surface were resistant to quinolones (Aoki et al., 2021) and macrolides in addition to fluoroquinolones (Hoshi et al., 2020). According to the World Health Organization (WHO), several bacteria like Klebsiella pneumoniae, E. coli, S. aureus, and Neisseria gonorrhoeae show resistance toward antibiotics like ciprofloxacin, carbapenem, fluoroquinolone, methicillin, third generation cephalosporins, sulphonamides, penicillin, tetracyclines, macrolides, fluoroquinolones, and early generation cephalosporins. Earlier, the WHO had published a list of pathogens developing resistance that require immediate attention for the development of new antimicrobials against them and Acinetobacter baumannii and P. aeruginosa were listed as “critical” priority targets (Shrivastava et al., 2018). It is predicted that $P$. aeruginosa causing ocular infections can develop resistance against beta-lactam, aminoglycoside, and fluoroquinolones. Genetic mutations and inter/intra-species transfer of mobile genetic elements was found to be the major cause of antibiotic resistance spread (Subedi et al., 2018). In another study, $42.9 \%$ of $P$. aeruginosa and $57.1 \%$ of Staphylococcus spp. isolated from corneal ulcers exhibited multidrug (MDR) resistance (Heidari et al., 2018). It was also found that MDR and MRSA isolates are increasing in serious ocular infections (Asbell et al., 2008). Ciprofloxacin and 
levofloxacin resistance among methicillin-sensitive $S$. aureus was also found frequently in corneal and conjunctival isolates (Marangon et al., 2004). Isolates of $P$. aeruginosa and $S$. aureus were also found to be resistant to ciprofloxacin, gentamicin, and cephalosporins (Willcox, 2011). Currently for management of MDR bacteria, antibiotics like linezolid, colistin, and imipenem are used (Egrilmez and Yildirim-Theveny, 2020). However from what we know about earlier antibiotics, the development of resistance against these antibiotics in bacteria may occur anytime soon. Similarly, the repertoire of effective antifungal agents remains very limited, with only three classes of drugs available for systemic therapy, polyenes (e.g. amphotericin B), triazoles (e.g. fluconazole), and echinocandins (e.g. caspofungin) (Nami et al., 2019). Fluconazole and ketoconazole show better intraocular penetration and acts against keratitis with deep lesions and are considered effective against both Candida and filamentous fungi (Chang and Chodosh, 2011). Natamycin is effective when it is topically administered; however, only $2 \%$ of the total drug is bioavailable in the cornea (O'day et al., 1986). Scedosporium spp. show resistance against amphotericin in vitro and both amphotericin $\mathrm{B}$ and miconazole show variable activity against Fusarium spp. (Klepser, 2011). Ketoconazole and itraconazole have poor in vitro activity against Aspergillus and Fusarium spp. (Pearce et al., 2009). Hence, several alternative therapeutic approaches are explored for the management of ocular microbial infections, some of them include corneal collagen cross-linking (Price and Price, 2016; Naranjo et al., 2019), photodynamic antimicrobial therapy (PDAT), and the use of antimicrobial peptides (AMPs), including host defense peptides and synthetic peptides. Alternative strategies are also required to develop antifungals as the development of drug resistance and limited availability of antifungals represent the main concerns for the current antifungal treatments. The major advantages of AMPs as an alternative are their broad-spectrum activity, rapid killing, anti-biofilm, lower chance of development of resistance, and low cytotoxicity to host. In the following sections, we have provided detailed description of AMPs and their protective role in preventing corneal keratitis.

\section{ANTIMICROBIAL PEPTIDES}

Antimicrobial peptides are a diverse group of small proteins that acts as the first line of defense and mounts an attack against invading pathogens. They are found to be evolutionarily conserved in the genome and synthesized by all forms of life (Hancock, 2000). In nature, AMPs are produced either by ribosomal translation of mRNA or by non-ribosomal peptide synthesis (Hancock and Chapple, 1999). In mammals, they are mainly found within granules of neutrophils; however, epithelial cells in the cornea, skin, or other mucosal sites also secrete AMPs. Often, several AMPs with different modes of action are encoded in a cluster of the genome and are co-expressed resulting in the accumulation of several AMPs at a specific site (Lai and Gallo, 2009). Due to their distinguished mode of actions, they are often effective against MDR isolates. Several AMPs are often produced in a catalytically inactive form and needs proteolytic cleavage to become active (Bals, 2000). AMPs are commonly classified based on their secondary structures as $\alpha$-helix, $\beta$-sheets, and random coil that lack a secondary structure. Antimicrobial peptides approved by the Food and Drug Administration (FDA) for clinical trials are listed in Table $\mathbf{1}$.

\section{Antimicrobial Peptides in Eye}

The cornea and ocular surface are protected from trauma and infection by physical and molecular defenses. The first effective defense involves eyelid closure and blinking, which protects the cornea from physical trauma and removes microbes from the ocular surface. In addition, ocular surface mucins and the tear film restrict pathogen interaction with the corneal epithelium (Mantelli and Argueso, 2008). Corneal epithelium is multilayered in nature and acts as the first line of defense during pathogen attack. Cornea expresses several AMPs (Figure 2) that have microbicidal properties or aids in wound healing, either constitutively or in response to microbial antigens ( $\mathrm{Mc}$ et al., 1999; Mcdermott, 2009; Sharma et al., 2018; Sharma et al., 2019). $\beta$-defensins are produced by the ocular surface and $\alpha$ defensins are supplied into the ocular surface fluids by resident or passing neutrophils and lacrimal ductular epithelia secretion (Kumar et al., 2006). Defensins are $3-4 \mathrm{kDa}$ cationic AMPs that are ubiquitous in nature and its structure contains six cysteine residues paired by disulfide bonds (Ganz and Lehrer, 1994). $\beta$-defensin-1 to -4 , liver expressed antimicrobial peptide (LEAP)-1 and -2, and LL-37/cathelicidin are often found in ocular surface epithelia (Paulsen et al., 2001). LEAP-1 is a cationic peptide made up of twenty five amino acids and contains four disulfide bonds (Krause et al., 2000). LL-37 is another cationic peptide consisting of 37 amino acids and is the only member of human cathelicidin family (Durr et al., 2006). Human $\beta$-defensin (hBD)- 1 is constitutively expressed in corneal and conjunctival epithelial cells whereas, in contrast, hBD-2 is rarely expressed in normal tissues. The corneal epithelial cells also constitutively express hBD-3, which some have found to be upregulated in response to cytokines (Mcdermott et al., 2003). hBD-4 is often found to be expressed in vitro, but rarely in vivo. hBD-9 is expressed by corneal and limbal epithelia and corneal stroma at modest levels, whereas conjunctival epithelium shows the presence of high levels of hBD-9 protein (Mohammed et al., 2010). LL-37 is expressed by both corneal and conjunctival epithelial cells (Gordon et al., 2005) and along with $\beta$-defensins contribute to the ability to resist pathogen attack by these cells (Augustin et al., 2011). S-100 class of proteins or calgranulins comprises a group of calcium-binding peptides that usually function as dimers (Fano et al., 1995). Constitutive expression of S100A7 has been reported in cornea, conjunctiva, nasolacrimal ducts, and lacrimal glands. S100A8 and S100A9 were also found to be expressed by human corneal stromal cells (Wilkinson et al., 2016). Ocular fluid also contains human neutrophil peptides (hNP-1 and -2), hBD-1, hBD-2, hBD3, lactoferrin, lysozyme, and transferrin during normal conditions (Silva et al., 2013). Lactoferrin, a member of transferrin family, is an iron-binding protein having different isoforms such as lactoferrin $\alpha, \beta$, and $\gamma$ (Anderson et al., 1990) 
TABLE 1 | Antimicrobial peptides in clinical trial.

\begin{tabular}{|c|c|c|c|c|}
\hline AMP & Source & Target & Phase & References \\
\hline hLF1-11 & Lactoferricin derivative & MRSA, K. pneumoniae, L. monocytogenes, fungal infections & $|/| \mid$ & Morici et al. (2016) \\
\hline PAC113 & Histatin-5 analogue & Oral candidiasis & II completed & $\begin{array}{l}\text { Mohammad et al. } \\
\text { (2015) }\end{array}$ \\
\hline POL7080 & Protegrin analogue & $P$. aeruginosa, $K$. pneumoniae & III & Butler et al. (2013) \\
\hline LTX-109 (Lytixar) & Synthetic peptide & Gram-positive MRSA skin infections & Ila completed & $\begin{array}{l}\text { Mohammad et al. } \\
(2015)\end{array}$ \\
\hline LL-37 & Human cathelicidin & Leg ulcer & Ilb & $\begin{array}{l}\text { Boparai and Sharma } \\
(2020)\end{array}$ \\
\hline Novexatin (NP213) & Cyclic cationic peptide & Fungal nail infection & $\| l b$ & Javia et al. (2018) \\
\hline D2A21 & Synthetic peptide & Burn wound infections & III & Ballweber et al. (2002) \\
\hline SGX942 & Synthetic peptide & Oral mucositis & III & Butler et al. (2017) \\
\hline PXL01 & Lactoferrin analogue & Postsurgical adhesions & III & Wiig et al. (2011) \\
\hline OP-145 & LL-37 derivative & Chronic middle ear infection & $\begin{array}{l}\text { Phase II } \\
\text { completed }\end{array}$ & Ming and Huang (2017) \\
\hline Mycoprex & Extracted from insects & Fungal infections & III & Hancock (2000) \\
\hline $\begin{array}{l}\text { Murepavadin } \\
\text { (POL7080) }\end{array}$ & Amino acid substitution of protegrin I & $\begin{array}{l}\text { Nosocomial pneumonia and ventilator-associated bacterial } \\
\text { pneumonia (VABP) }\end{array}$ & III & Butler et al. (2017) \\
\hline OP-145 & $\begin{array}{l}\text { Synthetic } 24 \text {-mer peptide derived } \\
\text { from LL-37 }\end{array}$ & Antibacterial, Chronic bacterial middle ear infection & II completed & Ming and Huang (2017) \\
\hline Histatin & Naturally occurring peptide & Oral candidiasis & Phase $\|/\| I$ & \\
\hline$M X-226$ & Cationic Peptide & Dermatology related infections & Phase III b & $\begin{array}{l}\text { Felício et al. (2017), } \\
\text { Boparai and Sharma } \\
(2020)\end{array}$ \\
\hline HB-107 & Cecropin B derivative & Wound healing & Preclinical & Mangoni et al. (2016) \\
\hline PL-5 & Alpha helical synthetic peptide & Treatment of skin infections & Phase ॥ & Feng et al. (2015) \\
\hline Daptomycin & Streptomyces roseosporus & Gram-positive bacteria & In market & $\begin{array}{l}\text { Cortes-Penfield et al. } \\
\text { (2018) }\end{array}$ \\
\hline
\end{tabular}

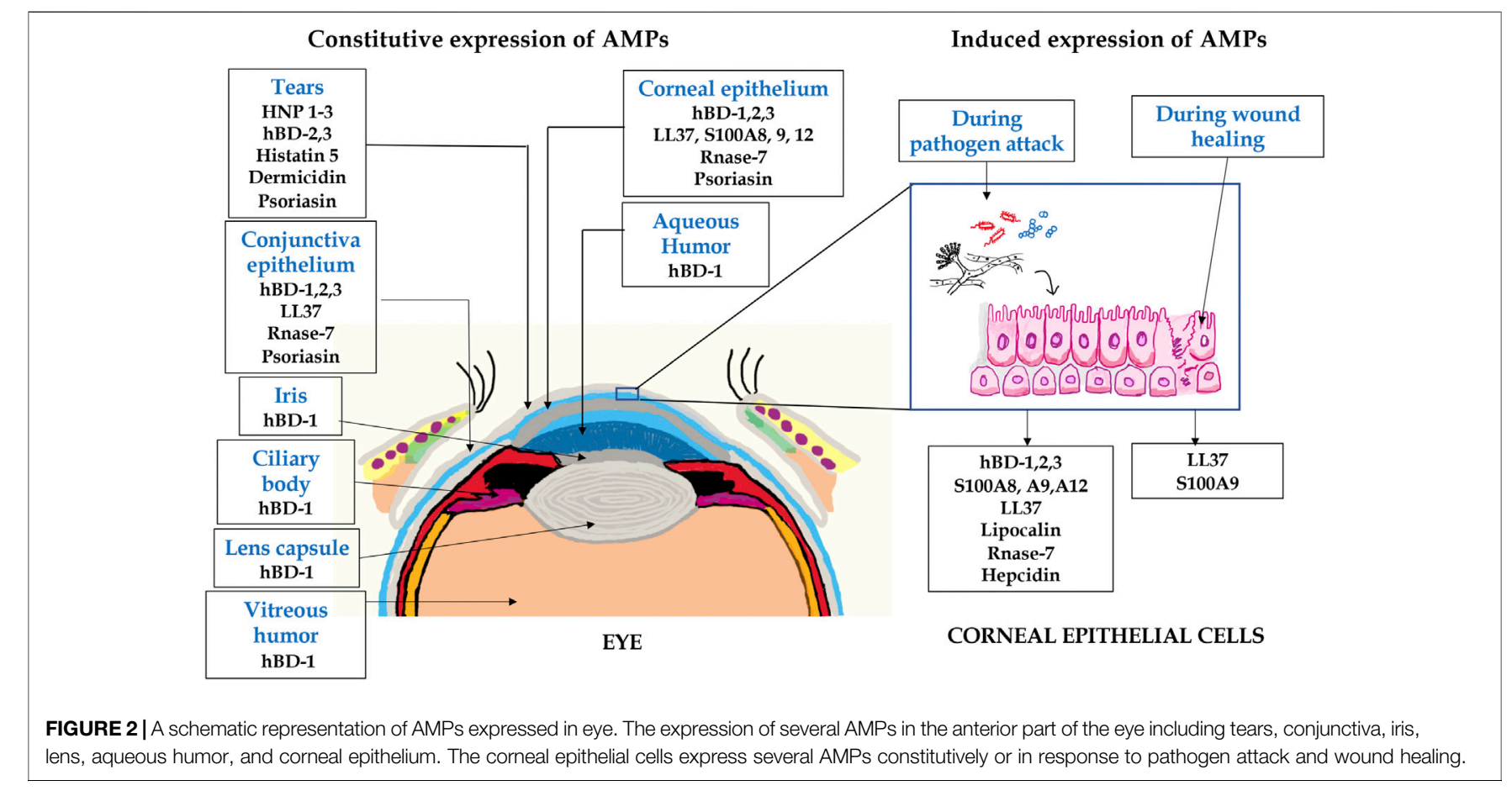

and plays an important role in human innate immune system (Baveye et al., 1999). Transferrin is another iron-binding glycoprotein that is responsible for the transport of iron in biological fluids (De Jong et al., 1990). Lysozyme, a $15 \mathrm{kDa}$ protein, present abundantly in tears hydrolyses bacterial cell wall (Mcdermott, 2013). The tear film also contains lactoferrin, $\beta$-defensins, calprotectin, and lipocalin (Dartt, 2011; Rusciano et al., 2018). Though their role in tears is not 


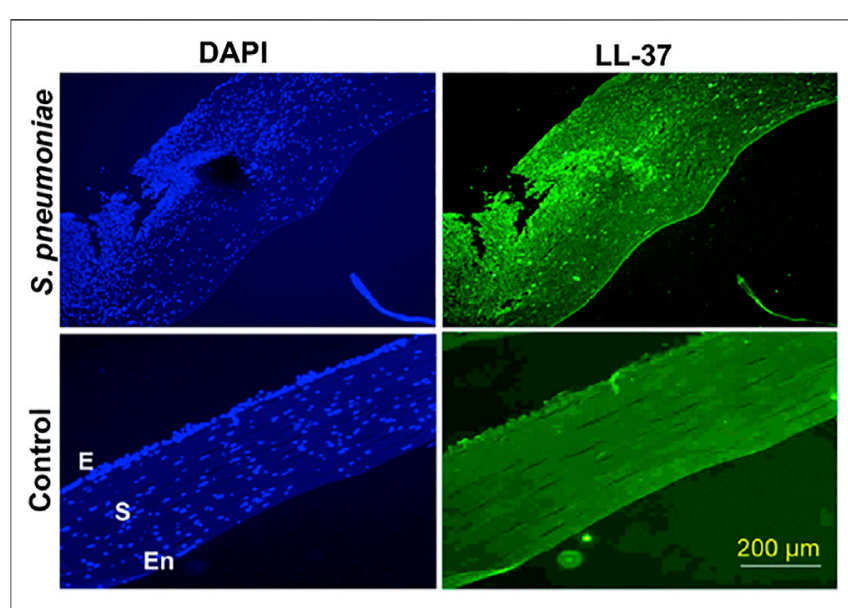

FIGURE 3 | LL-37 expression in corneal tissues obtained from S. pneumoniae keratitis patients. Corneal sections of keratitis patients obtained during corneal transplantation and control cadaveric corneas were stained with anti-LL-37 antibody, followed by Alexafluor 488 secondary antibody and imaged under a fluorescent microscope using 10X objective. The sections were counterstained with DAPI. E denotes epithelium, S-stroma, and Enendothelium. This figure is reprinted from reference Sharma et al. (2019).

fully known, it is likely that cation $\left(\mathrm{Fe}^{2+}\right.$ and $\left.\mathrm{Zn}^{2+}\right)$ sequestration in the ocular surface inhibits fungal germination and growth, which requires these essential metals. These constitutively expressed AMPs have a major role to play in the prevention of infections and aids in host defense. Murine $\beta$-defensin 3 (mBD-3, an orthologue of hBD-2) contributes to the clearance of $P$. aeruginosa in vivo and additionally limits $P$. aeruginosa adhesion to the corneal epithelial surface, thus suggesting that AMPs are also involved in maintaining normal resistance to infection in the healthy tissues (Augustin et al., 2011). hBD-2 is found more frequently in infected and inflamed ocular surface tissues. Bacterial products such as lipopolysaccharide (LPS) and pro-inflammatory cytokines such as interleukin (IL)- $1 \beta$ have been shown to upregulate hBD-2 expression in corneal and conjunctival epithelial cells in vitro through mitogen-activated protein (MAP) kinase and NF- $\kappa B$ pathways. Differential expression of several AMPs was identified in patients with $P$. aeruginosa and S. pneumoniae corneal infections (Sharma et al., 2018; Sharma et al., 2019). Increased expression of LL-37 was also detected in the corneal tissues obtained from patients with $S$. pneumoniae keratitis (Figure 3) (Sharma et al., 2019). hBD-9 was found to be downregulated in bacterial keratitis caused by both Gram-positive and Gram-negative bacteria (Mohammed et al., 2010). hBD-3 and RNAse7 were found to be significantly increased in corneal epithelial cells in response to A. castellanii (Otri et al., 2010). A significant increase in the expression of S100A8, S100A9, and hBD-1 was observed both in vitro and in corneal ulcers of patients during the Corynebacterium pseudodiphtheriticum infection (Roy et al., 2015). Mohammed et al. (2020) observed increased expression of hBD-1, 2, and 9 in patients with fungal keratitis. However, we have found reduced expression of $\beta$-defensins in patients with A. flavus corneal infections (Mallela et al., 2021).

\section{Natural Peptides}

Peptides are broadly classified into two classes based on their origin, natural peptides, and synthetic peptides. Natural peptides are secreted by a large number of different species such as bacteria, virus, amphibians, mammals, insects, and plants. These peptides can act as natural ligands either as agonists or antagonists and are highly selective and well tolerated. Bacterial infection causes upregulation of several host defense peptides that helps to combat the attack of pathogens. hBD-2 was frequently reported in infected/inflamed ocular surface tissues. Increased expression of defensins was also observed in a murine model of corneal infections, and $\mathrm{mBD}-3$ increased resistance to Pseudomonas corneal infections and modulate Toll-like receptor (TLR) signaling in the infected corneas (Wu et al., 2009). Ocular commensal like C. mastidis has been shown to induce IL-17 expression that elicits the release of AMPs into tears and protect against $P$. aeruginosa infections (St Leger et al., 2017). The topical application of OH-CATH30, an AMP identified in king cobra is efficacious against drug-resistant $P$. aeruginosa keratitis (Li et al., 2014). LL-37 showed potent antibacterial activity against both laboratory strain and ocular clinical isolates of S. pneumoniae (Sharma et al., 2019). It also showed antibacterial activity against $S$. aureus and $S$. epidermidis. Cathelicidin deficit mice also showed increased susceptibility to $P$. aeruginosa keratitis (Huang et al., 2007). S100A8/A9 was found to induce reactive oxygen species (ROS) and aided in macrophage-mediated bacterial killing during $P$. aeruginosa keratitis (Deng et al., 2013). Lipocalin present in tear was reported to inhibit both bacterial and fungal growth (Fluckinger et al., 2004) and also suppressed ocular inflammation in LPS-induced uveitis (Tang et al., 2018). The antimicrobial peptide Css54, isolated from the venom of Centruroides suffuses, was found to exhibit antimicrobial activity against bacteria such as Listeria monocytogenes, Streptococcus suis, Campylobacter jejuni, and Salmonella typhimurium that cause zoonotic diseases (Park et al., 2020). Using a high-throughput technique of the phage display method, 12-mer peptide phage display library was screened to identify peptides effective against infectious keratitis. Both Pc-C and Pc-E peptides inhibit the adhesion of $A$. fumigatus to human corneal epithelial cells (HCEC) and decreased fungus-mediated corneal disruptions in a mice model of keratitis (Zhao et al., 2012). Endogenous expression of $\mathrm{mBD} 3, \mathrm{mBD} 4$, and CRAMP was found to play an important role in $F$. solani keratitis (Kolar et al., 2013). Increased expression of LL-37, hBD-2, and hBD-3 in corneal epithelial cells was also noted in response to heat-killed $C$. albicans (Hua et al., 2014). Cullor et al. (1990) found defensins, NP-1, and NP-5, effective against C. albicans' ocular isolates found in humans and horses. A study by Sengupta et al. (2012) reported the antifungal activity of lactoferricin $\mathrm{B}$ against fungal pathogens and its effect on eradication of the biofilms from contact lenses. Lactoferricin B helps to decrease the dosage of antifungal agents by 8 folds against biofilms formed by $A$. fumigatus, F. solani, or C. albicans. Another study reported that $a$ defensins are known to show strong antifungal activity against A. fumigatus, C. neoformans, and C. albicans (Delliere et al., 2020). Histatin -5 is a histidine-rich peptide which is 
produced by salivary glands in humans and higher primates ( $\mathrm{Du}$ et al., 2017). Both hNP-1 and histatin-5 were found in human saliva exhibiting candidacidal activity due to their non-lytic release of mitochondrial ATP and chelation of the metal ions (Helmerhorst et al., 2001). hBD-1, -2, -3, histatin-5, and LL-37 were found to show fungicidal activity against Candida spp. via secreted glycosylated exodomain protease, Msb2 (Swidergall et al., 2013). Human cathelicidin and $\beta$-defensins permeabilize the cell membrane of the yeast that leads to the death of the fungi (van Der Weerden et al., 2010). HBD-3 and LL-37 bind to the $\beta-1$, 3-exogluconase of the cell wall of C. albicans, thereby reducing its infectivity toward the host (Mohammed I. et al., 2017). Histatin-5 kills the fungus by different mechanisms, it activates the stress response pathways and secretion of the proteases. Histatin-5 enter into the fungus via Dur3/Dur 31 transporters, induce ATP efflux and release of ROS, and finally activate the high osmolarity glycerol stress response pathway, followed by extrusion of histatin-5 via efflux transporter, Flu1 (Edgerton et al., 2000). RNase-3 and RNase-7 were known to show fungicidal activity at lower micromolar concentration against C. albicans by perturbing the cellular RNA and disturbing the stability of the cell membrane (Berman, 2012). A reduced form of psoriasin (S100A7), a linear peptide, showed killing activity against $A$. fumigatus by chelation of zinc metals and leading to fungal apoptosis (Mohammed I. et al., 2017). Calprotectin (S100A8/A9) exhibited antifungal activity, blocked hyphal growth, and limited the growth of Aspergillus spp. by inhibiting transport of fungal zinc and manganese in a mouse model of keratitis (Clark et al., 2016).

\section{Synthetic Peptides}

Synthetic or semi synthetic peptides are generally designed to upregulate the pharmacological properties and to overcome the limitations of naturally derived AMPs including host toxicity, degradation by proteases, and loss of antimicrobial activity in presence of physiological salt concentration (Mohamed et al., 2016). The short synthetic peptides have high electivity and reduced cost of production making them ideal for translational clinical application. Several peptides designed and synthesized have been tested against various bacteria and fungus both in vitro and in vivo. EC1-17KV, synthetic peptides based on the antimicrobial peptide EeCentrocin 1 from Echinus esculentus, was efficient in killing MDR P. aeruginosa and exhibited multiple modes of action, including direct membrane disruption and inhibitory effects on cell adhesion and biofilm formation (Ma et al., 2020). Another novel short $a$-helical hybrid peptide inspired by natural $a$-helical AMPs, PA-13, showed remarkable broad-spectrum antibacterial activity, especially against $P$. aeruginosa with no toxicity to mammalian cells. It displayed rapid binding and penetration activity which resulted in membrane permeabilization and also exhibited an antiinflammatory response by neutralizing LPS (Klubthawee et al., 2020). Pam-3, a palmitoleic acid-modified octapeptide fragment designed from hBD-1, was found to be effective in vitro against multidrug-resistant ESKAPE pathogens (six nosocomial pathogens, Enterococcus faecium, S. aureus, K. pneumoniae, A. baumannii, $P$. aeruginosa, and Enterobacter species that exhibit multidrug resistance and virulence). Pam-3 is also highly effective against $A$. baumannii resistant to the last-resort antibiotics, colistin and tigecycline. Additionally, Pam-3 was able to eradicate established biofilms formed by $S$. aureus and $P$. aeruginosa in vitro (Koeninger et al., 2021). SAAP-148, a synthetic LL-37 inspired peptide, is highly effective against MDR Gram-positive and Gram-negative ESKAPE pathogens, as well as isolates of E. cloacae, E. coli, and K. pneumoniae resistant to the last-resort antibiotic colistin. SAAP-148 was also able to kill Clostridium difficile under anaerobic conditions and successful in preventing the formation and eradication of established biofilms by $S$. aureus and $A$. baumannii (De Breij et al., 2018). A synthetic peptide, TC19, derived from the human thrombocidin-1-derived peptide L3, showed efficient and rapid killing in human plasma of MDR strains of several ESKAPE bacterial species. FK16, a cathelicidinderived shorter peptide, was found to show increased killing ability toward $P$. aeruginosa, by itself or in synergy with vancomycin without having any toxicity to the host (Mohammed et al., 2019). A hybrid peptide of cecropin A and mellitin (derived from venom of European honey bee) was found to be effective against $P$. aeruginosa in a rabbit model of keratitis (Nos-Barbera et al., 1997). Cationic antimicrobial protein (CAP37)-derived peptide analogues showed significant antifungal activity against multifarious Candida species from patients with vulvovaginitis. Bactericidal permeabilityincreasing (BPI) protein, a cationic protein derivative has broad spectrum activity against many fungi, including Candida spp., C. neoformans, and A. fumigatus. Shorter synthetic peptides (XMP.284, XMP.366, and XMP.39 1) which are derivatives of BPI protein domain III analogs act against Candida spp. When these peptides were used in combination with flucanozole, the minimum inhibitory concentration (MIC) of the antibiotic reduced up to 8 -fold. The peptide XMP 391 was effective against murine-disseminated aspergillosis and enhanced the effectiveness of amphotericin B. The peptides ToAP2 (derived from venom of scorpion Tityus obscurus) and NDNP-5.7 also showed antifungal properties against C. albicans infection in which ToAP2 exhibited a broad spectrum of activity. These peptides show fungicidal nature by permeabilizing the cell membrane and invoked changes in cell morphology such as cell disruption 24-h posttreatment (Do Nascimento Dias et al., 2020). P10, an $\alpha$-helical amphipathic AMP, exhibited an enhanced antimicrobial spectrum against. C. albicans and A. niger (Kang et al., 2017). Lipopeptides, which were secreted by the $P$. syringae, was particularly active against several filamentous fungi and yeasts, including Candida, Cryptococcus, and Aspergillus strains (De Luca and Walsh, 2000). Cecropins, an AMP derived from insects, exhibited antifungal properties against Aspergillus and Fusarium spp. (Andra et al., 2001). This peptide targets the cell membrane by disrupting it and creates ionic imbalance and intracellular redox states in C. albicans. The upregulation of expression of CRAMP, a mouse analogue of human LL-37, leads to a decrease in the gastrointestinal colonization of $C$. albicans (Niyonsaba and Ogawa, 2005). The peptide proteagrin-1 from porcine was particularly active against a broad range of fungi, including several Candida spp. 
A

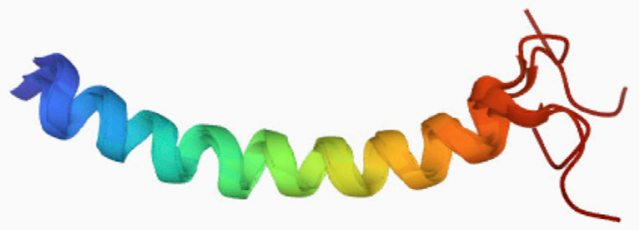

B

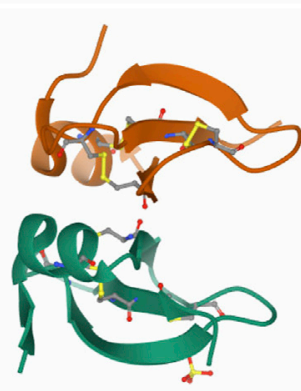

C

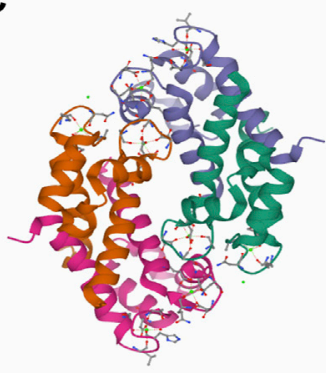

FIGURE 4 | Representative structures of AMPs. Structures of LL-37 (Wang, 2008) (A), hBD-2 (Hoover et al., 2000) (B), and crystal structure of human calprotectin (S100A8/S100A9) (Korndorfer et al., 2007) (C).

(including drug-resistant strains) and Cryptococcus neoformans (Buda De Cesare et al., 2020). The same study also reported other peptides like SMAP-29 (cathelicidin in ovine), BMAP-27, and BMAP-28 (two bovine $\alpha$-helical) to be effective as proteagrin-1 against C. tropicalis, C. glabrata, and C. parapsilosis (Buda De Cesare et al., 2020).

\section{Mode of Action of Antimicrobial Peptides}

In general, AMPs are cationic in nature with a net charge of +2 to +11 and an amphipathic structure that aids in insertion in bacterial cell membrane either as alpha-helices or beta-sheets (Luong et al., 2020). Representative structural images of few AMPs are given in Figure 4. Cationic AMPs selectively bind to the negatively charged surface of the bacterial membrane (Matsumoto et al., 2006; Strahl and Errington, 2017) that differ from mammalian cell membranes consisting of neutral phospholipids (Van Meer et al., 2008). In case of fungi, AMPs inhibit or kill the pathogenic fungi by inhibiting the spore germination or mycelial growth or by causing the structural deformity in the spores/hyphae by creating pores, twists, and making them swollen and broken (Li et al., 2021). Most of the AMPs show a direct action against pathogens by creating pores on their membrane, hence causing leakage and cell death. The models for the creation of pores on the cell membrane by AMPs that have been hypothesized are as follows:

a. Barrel-stave model, where AMPs form bundles and insert in the membrane like a cylinder creating pores, hydrophobic region of peptide interacting with lipid part, and ultimately causing leakage (Bocchinfuso et al., 2009; Zeth and SanchoVaello, 2017). For example, dermicidin and GA IV glycotriazole peptides (Junior et al., 2017).

b. Toroidal model, where AMPs arrange and implant themselves vertically in the membrane to make pores and forces the lipids to form micelles and hence disrupts the membrane (Matsuzaki et al., 1995). For example, magainin 2.

c. Carpet-like model, where AMPs form aggregates and arrange parallelly on the membrane like a carpet and intercalate into the membrane, with hydrophobic sites facing the membrane and disrupts the arrangement of the lipid bilayer (Oren and Shai, 1998). For example, LL37 and PMAP-23.

Apart from these classical models, AMPs like R9F2 and (KFF) $3 \mathrm{~K}$ have recently been shown to cause cell wall thinning, loss of cytoplasm structure, formation of mesosome-derived multimembrane structures, and "decorated fibers" derived from DNA chains in S. aureus (Grigor'eva et al., 2020) instead of pore formation. EP-2, an antifungal peptide isolated from $B$ subtilis, can swell and distort the mycelium of the fungi thereby inhibiting the growth of fungi (Wang et al., 2016). As fungal cells are mainly composed of polysaccharides, $\beta$-glucans, chitin, and mannan, AMPs inhibit the synthesis of these saccharides (Li et al., 2021). Anidulafungin, a synthetic lipopeptide, inhibits the synthesis of $1,3 \beta$-D glucan synthesis in the cell walls of Candida and Aspergillus (Martin Mazuelos and Rodriguez-Tudela, 2008). Apart from cell membrane disruption, some AMPs like Bac 7, PR-39, and HNP-1 (Cardoso et al., 2019) are also involved in the inhibition of protein biosynthesis or nucleic acid biosynthesis (Hale and Hancock, 2007); some like histatin-5 causes protease activity, others like pyrrhocoricin and drosocin (Nielsen et al., 2021) causes disruption of DnaK activity. Indolicidin, aurein, magainin II, cecropin A, and LL-37 were also found to enhance the essential lipid transportation causing rapid scrambling of the lipid composition leading to an increase in ion transport and activation of lethal signaling processes (Paredes-Gamero et al., 2012). Apart from their direct microbicidal activity, AMPs also help in the chemotaxis of host neutrophils, mast cells, and monocytes, phagocytosis, angiogenesis, and wound healing. AMPs can also trigger mast cell degranulation and lead to increased blood vessel permeability. Hence, AMPs can target a pathogen directly or indirectly, ultimately leading to clearance and healing. It has also been shown that some AMPs at lower concentrations activate apoptosis and hence lead to regulated cell death (Lee and Lee, 2014).

\section{OTHER COMPOUNDS}

During corneal infections, pro-inflammatory cytokines like IL$1 \beta$, IL-6, and tumor necrosis factor (TNF)- $\alpha$ are released that triggers different signaling pathways leading to collagen degradation in the stroma as well as necrotic death of keratocytes. These inflammatory damages result in the thinning of corneal stroma followed by scar formation (Yan et al., 2017; Crupi et al., 2019). Studies have reported that the topical antioxidants or corticosteroids or lipid treatment reduced the inflammatory reaction that occurs during acute corneal inflammation and protects the ocular damage (Alio et al., 1995; Lim et al., 2015; Ni et al., 2016a). Here, we will be 
discussing about the antioxidants, small molecules, lipids, and corticosteroids that were used to protect the eye from fungal, bacterial or bacterial toxin-induced inflammatory damage.

\section{Antioxidants}

The generation of ROS by corneal epithelial cells (CEC) often protects corneas from microbial infections by killing the microbes; however, excess production of ROS induces corneal inflammation and results in irreversible corneal opacification and loss of vision (Ruban et al., 2018). Antioxidants reduce the free radical by donating their electrons and decrease the inflammatory damage of CEC. Various studies have reported the usage of antioxidants to protect the cornea from the microbial-induced inflammatory damage. Resveratrol, a naturally occurring phytoalexin produced in the fruits and leaves of edible plants is known to possess antioxidant and anti-inflammatory activity (Iyori et al., 2008; Speciale et al., 2011). Resveratrol downregulates pro-inflammatory cytokines in cells by suppressing the activation of NF- $\kappa$ B. Marino et al. (2013) found that resveratrol protected the cornea from $S$. aureus-induced inflammatory damage by downregulating the expression of TLR2 and IL-8 in an ex vivo model of infection. Tempol (4-hydroxy-2,2,6,6tetramethylpiperidine-1-oxyl), a membrane permeable molecule known to exhibit antioxidant activity, reduces the reactive oxygen and nitrogen species and enhances the catalytic activity of catalase (Batinić-Haberle et al., 2010; Wilcox, 2010). Crupi et al. (2019) used this potent antioxidant molecule to explore its protective effect against LPS-induced corneal cell damage and found that tempol protected the corneal cells from inflammatory damage by enhancing the antioxidant activity of SOD and lowering the prostaglandin E2 (PGE2) levels, cytokines, and COX-2 expression. Asiatic acid (a triterpenoid) was found to protect HCEC from the LPS-induced inflammatory damage by inhibiting p-Akt activation, downregulating inflammatory cytokines, and upregulating antioxidant activity (Chen et al., 2017). Quercetin is a natural flavonoid known for antioxidant activity along with antiinflammatory, antitumor, and cardiovascular protective activity (Li et al., 2016). Previous studies have reported that quercetin exerts antifungal activity against wide variety of fungal strains (Rocha et al., 2019) and also reported the suppression of LPSinduced retinal inflammation in mice (Ho et al., 2020). Yin et al. (2021) reported protective effect of potential quercetin against $A$. fumigatus-induced corneal keratitis. In vitro studies showed that quercetin treatment significantly reduced the growth of $A$. fumigatus without affecting the viability of HCEC, whereas in in vivo studies, it reduced the fungal load in the cornea with minimal recruitment and infiltration of neutrophils to the corneal stroma (Yin et al., 2021). Baicalein, a flavonoid isolated from Scutellarin baicalins, is also known to have an antioxidant activity along with antifungal and anti-inflammatory applications (Zhu et al., 2021). Zhu et al. (2021) have reported the use of baicalein to protect the cornea from $A$. fumigatus infection in a murine model of keratitis. Treatment of infected mice cornea with baicalein significantly reduced fungal growth, biofilm formation, adhesion, and suppressing inflammatory responses via downregulating the thymic stromal lymphopoietin (TSLP)/TSLP receptor (TSLPR) pathway (Zhu et al., 2021). Epigallocatechin gallate (EGCG) is a polyphenol obtained from the green tea is known to have good antioxidant and anti-inflammatory activity (Ruban et al., 2018). Topical administration of voriconazole along with EGCG showed the inhibition of $F$. solani-induced keratitis by reducing the fungal growth and inflammatory responses. Systemic supplementation of vitamin $\mathrm{C}$ (ascorbic acid) showed reduced corneal opacity caused by infectious keratitis (Cho et al., 2014). Vincamine, an alkaloid with strong antioxidant activity, protected HCEC against LPS-induced oxidative and inflammatory damage by scavenging ROS and reducing the expression of IL- $1 \beta$, IL-6, IL-8, TNF- $\alpha$, and the transforming growth factor (TGF)- $\beta$ (Wu et al., 2018). Antioxidants having anti-inflammatory activity have advantages in protecting the cornea from the microbial toxin-induced inflammatory damage during corneal keratitis.

\section{Small Molecules}

To fight the antibiotic resistance that is increasing rapidly on a global scale, the virulence factors of the pathogens are often targeted and explored as alternative therapeutic agents. Highthroughput screening are being widely used to identify various compounds that could be developed as small molecule tools to study the pathogen further or as a treatment for preventing infections. Dajcs et al. have reported the inhibitory role of lysostaphin, a zinc metalloproteinase obtained from $S$. simulans, against $S$. aureus-induced corneal keratitis. In vivo studies (rabbit models) displayed that lysostaphin treatment significantly killed more methicillin resistant $S$. aureus (MRSA) or methicillin sensitive $S$. aureus on the corneal surface and the corneal tissues than in vancomycin-treated or untreated eyes (Dajcs et al., 2000). Further, the authors also evaluated possible allergic reactions toward lysostaphin and found no adverse reactions (Dajcs et al., 2002). Small molecule like 2-Imino-5-arylidene thiazolidinone was found to inhibit type II secretory system of $P$. aeruginosa and type 3 secretory system (T3SS) in Yersinia spp. (Felise et al., 2008). Recently Sharma et al. (2020) have shown that INP0341, a salicyledene acylhydrazide that blocks T3SS, effectively inhibits Pseudomonas infection in a murine model of keratitis. The salicyledene acylhydrazides block the T3SS in several pathogens, including Y. pseudotuberculosis (Nordfelth et al., 2005; Bailey et al., 2007), C. trachomatis (Slepenkin et al., 2011), S. enterica, and P. aeruginosa. Several small-molecule compounds that inhibit Pseudomonas elastase have been reported by various groups (Burns et al., 1990; Cathcart et al., 2011; Konstantinovic et al., 2020). The compound 2mercaptoacetyl-L-phenylalanyl-L-leucine, effectively inhibited elastase activity in rabbit corneas and reduced corneal melting in a rabbit model of $P$. aeruginosa keratitis (Spierer and Kessler, 1984). Targocil, a teichoic acid biosynthesis inhibitor, significantly reduced intracellular growth of $S$. aureus in HCEC and further aided in reducing the adherence of $S$. aureus to corneal cells (Suzuki et al., 2011). Very recently, pseudolipasin A, an inhibitor of ExoU of $P$. aeruginosa, induced scratch healing and reduced cell death of human corneal epithelial cells during $P$. aeruginosa infection (Foulkes et al., 2021). Glycyrrhizin, a glycoconjugate triterpene isolated from G. glabra, significantly reduced the adherence of $P$. 


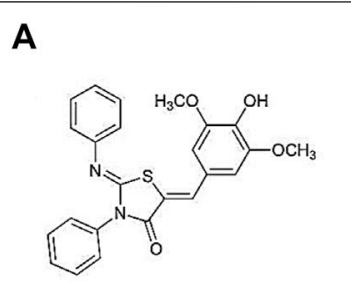

$B$
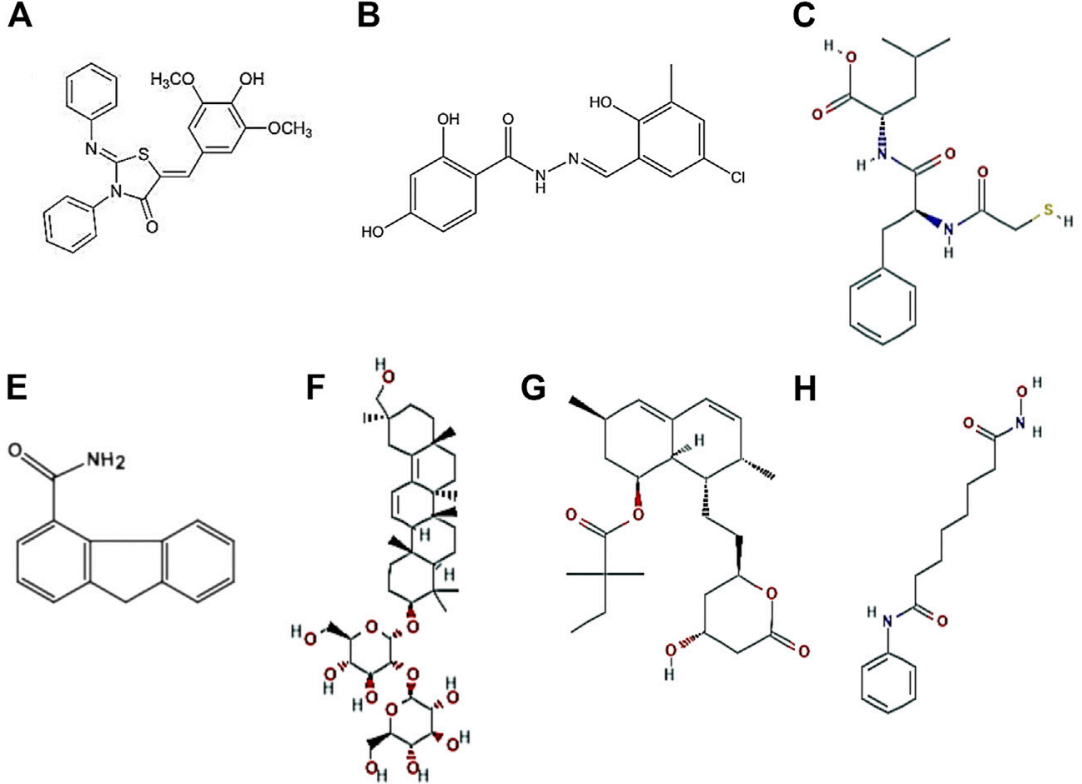
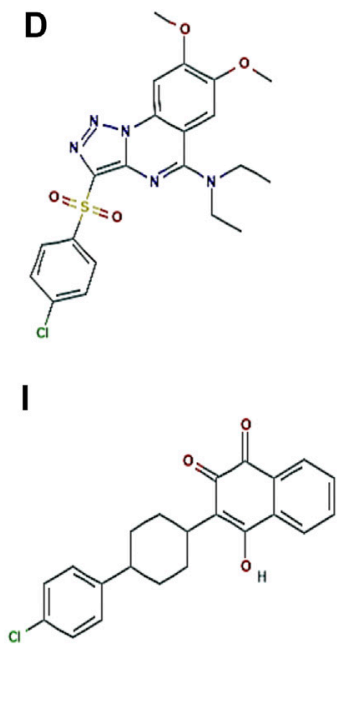

FIGURE 5 | Representative structures of small molecules. 2-Imino-5-Arylidene thiazolidinone (Felise et al., 2008) (A), INP0341 (Nordfelth et al., 2005) (B), 2mercaptoacetyl-L-phenylalanyl-L-leucine (Kessler et al., 1982) (C), Targocil (Farha et al., 2015) (D), Pseudolipasin A (Lee et al., 2007) (E), Glycyrrhizin (Ji et al., 2016) (F), Simvastatin (Jensen et al., 2016) (G), Suberoylanilide hydroxamic acid (Choi and Pflum, 2012) (H), and Atovaquone (Nixon et al., 2013$)$ (I).

aeruginosa to corneal epithelial cells and inhibited the growth of bacteria in a mouse model of Pseudomonas corneal infections, either alone or in combination with antibiotic (Hazlett et al., 2019). Topical application of simvastatin that blocks HMG-CoA reductase required for siderophore biosynthesis, significantly reduced fungal burden during $A$. fumigatus corneal infections by restricting fungal iron acquisition in vivo (Leal et al., 2013). Very recently suberoylanilide hydroxamic acid, a histone deacetylase inhibitor, significantly reduced inflammation and expression of pro-inflammatory cytokines in a murine model of F. solani keratitis ( $\mathrm{Li}$ et al., 2019). Atovaquone, a hydroxynapthaquinone, acts as an antifungal agent by disrupting mitochondrial functions and intracellular zinc storage in Aspergillus spp. and Fusarium spp. Reduced hyphal growth was observed in murine eyes infected with Fusarium and treated with atovaquone compared to infected eyes (Clark et al., 2018). The represented structures of the small molecules are presented in Figure 5.

\section{Lipids}

The omega-3 fatty acids like docosahexaenoic acid (DHA) and eicosapentaenoic acid (EPA) exhibits anti-inflammatory activity by inhibiting the oxidation of arachidonic acid (AA), which prevents the production of pro-inflammatory molecules like leukotriene $\mathrm{B}_{4}$ and prostaglandin $\mathrm{E}_{2}$ (Lim et al., 2015). Resolvins, an endogenous lipid mediator derived from EPA (resolvin $\mathrm{E}, \mathrm{RvE}$ ) and DHA (resolvin $\mathrm{D}, \mathrm{RvD}$ ) exhibits antiinflammatory activity by reducing the production of proinflammatory cytokines. Among E-series resolvins, RvE1 possess various biological activities, including antioxidant and anti-inflammatory properties, and also they clear neutrophils from the site of inflammation by recruiting non-inflammatory monocytes and macrophages. This potential molecules was used by Lee et al. (2015) to evaluate its protective effect from bacterial toxin(LPS, antibiotic-killed S. aureus and P. aeruginosa)-induced corneal inflammatory damage. RvE1 treatment significantly reduced the production of chemokines and pro-inflammatory cytokines in HCEC, human neutrophils (IL-6, IL-8, and CXCL1), murine cornea (CXCL1), and macrophages (CXCL1, TNF- $\alpha$, and IL-1 $\beta$ ). Additionally, RvE1 treatment also reduced the neutrophil infiltrations into the corneal stroma and minimized corneal thickness and haze. RvD1 prevented the corneal inflammatory damage by reducing corneal infiltrates, edema, and production of inflammatory cytokines (IL-6 and CXCL1) along with inhibition of neutrophil recruitment (Lee et al., 2016).

\section{Corticosteroids}

Corticosteroids having anti-inflammatory activity are known to suppress inflammatory pathways in a wide variety of cells by downregulating the inflammatory genes (Tallab and Stone, 2016). Corticosteroids were used for its anti-inflammatory property to treat bacterial keratitis in combination with antibiotics, in addition they also reduce scarring, stromal melts, and neovascularization (Austin et al., 2017; Ni et al., 2016b). However, the use of topical corticosteroids has always been a topic of debate. There are several studies that report use of corticosteroids to be helpful in reducing severity of corneal stromal melt and neovascularization and improve patient compliance by alleviating pain and discomfort. It has also been shown to reduce neutrophil chemotaxis and thus lower cytokine burden. On the contrary, use of corticosteroid in bacterial keratitis has been argued to delay epithelial healing 
and exacerbation of infection (Gritz et al., 1992). Several animal models were developed to explore the protective effect of corticosteroids from microbial keratitis (Bohigian and Foster, 1977; Badenoch et al., 1985; Gritz et al., 1992). Usage of corticosteroids alone for treating microbial keratitis enhanced the microbial count and extended infection period that leads to the corneal stroma thinning and perforation (Badenoch et al., 1985; Hazlett et al., 2016), whereas, in combination with antibiotics they neither have an effect on antimicrobial activity nor on the final outcome of corneal anatomy (Hindman et al., 2009). Animal studies have also displayed that topical administration of corticosteroids after corneal injury decreased corneal wound healing strength (Sugar and Chandler, 1974). Previous clinical trials have reported the use of corticosteroids in treating corneal keratitis and steroids for corneal ulcers trial (SCUT). A clinical study performed by Carmichael et al. (1990) reported that patients treated with antibiotics only (fortified cefazolin $32 \mathrm{~g} / \mathrm{L}$ and gentamicin $14 \mathrm{~g} / \mathrm{L}$ ) and antibiotics plus steroids (fortified cefazolin $32 \mathrm{~g} / \mathrm{L}$, gentamicin $14 \mathrm{~g} / \mathrm{L}$, and $0.1 \%$ dexamethasone) showed no statistically significant difference in the outcome in terms of best corrected vision and the ulcer healing rate. A randomized clinical study was carried out by Blair et al. (2011) to investigate the protective effect of antibiotics (gatifloxacin) and antibiotics plus corticosteroids (gatifloxacin plus $0.1 \%$ dexamethasone) on the bacterial corneal ulcers. The mean residual ulcers measured by clinician at 10 weeks showed a smaller change in the ulcers size of antibiotics plus corticosteroids-treated patient than the only the antibiotictreated patients group, though the difference was not significant. A preliminary clinical trial was carried out by Srinivasan et al. (2009) to evaluate the effect of adjunctive topical corticosteroids on the outcome in bacterial keratitis. Patients treated with corticosteroid (prednisolone sodium phosphate $1 \%$ ) after moxifloxacin (0.5\%) showed significant delay in re-epithelialization than control patients (corticosteroids-untreated patients).

\section{ANTIMICROBIAL PEPTIDES AND ALTERNATIVE THERAPEUTICS IN OCULAR WOUND HEALING}

Corneal wound healing consists of complex sequences of events involving the regeneration of epithelial layers, migration of epithelial cells, fibroblasts for wound closure, and regeneration of tissues in a regulated manner so that the transparency of the cornea is not compromised. Corneal epithelial cells aid in the process by replenishing themselves and mediating cell signaling and crosstalk with stromal cells (Di Girolamo, 2015). The wound healing is facilitated by several growth factors, cytokines, and endogenous AMPs expressed by CEC. Several AMPs that are upregulated in patients with bacterial or fungal corneal infections, like $\beta$-defensins, LL-37, S100A8, S100A9, and Reg3 $\gamma$ (Sharma et al., 2018; Sharma et al., 2019), have been shown to also possess wound-healing properties. hBD-2 mRNA was found to be upregulated in the epithelium of wounded corneas and aided in regeneration of corneal epithelium (Mcdermott et al., 2001).
hBD-2 also induced expression of several cytokines and enhanced rapid intracellular $\mathrm{Ca}^{2+}$ influx that helped in proliferation of keratinocytes in a skin wound model (Mi et al., 2018). Histatin-5 was found to promote cell migration and accelerate wound closure in murine model of corneal epithelial injury (Shah et al., 2020). Increased expression of LL-37 was noted in regenerating corneal epithelium and induced migration of corneal epithelial cells (Huang et al., 2006). Other reports have also shown that LL-37 induced wound healing in the porcine corneal wound model by activation of EGFR signaling via PI3K/ Akt and ERK signaling pathways (Yin and Yu, 2010). Cationic antimicrobial protein, CAP37, interacts with TLR4 and promotes corneal re-epithelization in mice (Kasus-Jacobi et al., 2020). Very recently, a dipeptide, isolated from human placental extract has been found to accelerate corneal wound healing both in vitro and in vivo (Nagata et al., 2015). RNase 5 has been shown to facilitate corneal wound healing in rabbit by activation of the PI3K/Akt pathway (Kim et al., 2016). Apart from AMPs, small molecules like Y-27632, a Rho-associated protein kinase inhibitor, has also been shown to induce proliferation of limbal stem cells and improve wound healing in in vivo mouse model (Sun et al., 2015) by modulation of cell-cell adhesion. Several lectins have also been shown to promote regeneration of corneal epithelium. $\mathrm{KM}+$, a lectin obtained from Artocarpus integrifolia, promotes neutrophil migration and restoration of corneal epithelium in a rabbit corneal wound model (Chahud et al., 2009). Galectin 3 and galectin 7 have also shown to accelerate wound healing in a corneal alkali burn model (Cao et al., 2003). Acacia honey has been reported to accelerate corneal wound healing in rabbit corneal fibroblasts in vitro (Abd Ghafar et al., 2016). Another traditional herbal medicine, Centella asiatica, helped in proliferation and migration of rabbit corneal epithelial cells (Ruszymah et al., 2012). These data show promises that AMPs or their derivatives and mimetics can be potentially be useful to promote wound healing following corneal damages due to accidental injuries, or various surgeries.

\section{OCULAR DRUG DELIVERY SYSTEMS TO TREAT KERATITIS}

Treatment of cornea appears to be easily accessible; however, various physicochemical barriers hinder the drug penetration into this tissue. In addition to this, other factors, like excess tear secretions, blinking reflex, and nasolacrimal drainage system, significantly reduces drug retention time in the ocular surface; only $1-7 \%$ of the available drug reaches the corneal stroma (Hewitt et al., 2020). Therefore, a high dosage of the drugs are required for treating the infections, and nasolacrimal regions exposed to those drugs lead to adverse side effects (Phan et al., 2014; Djebli et al., 2017). In order to minimize high usage of drugs and reduce their side effects, the drugs need to be delivered to the site of infection. Drug delivery systems play a critical role in delivering the drugs to the infected sites. In this section, we will discuss the different types of drug delivery systems for delivering therapeutics to treat corneal infections. 


\section{Contact Lens}

Contact lenses (CLs) are transparent, concave-shaped devices directly placed on the ocular surface for correcting the refractive errors. Additionally, they are used as bandage for protecting the corneal epithelial layer, helping in healing, and sealing wound leaks (Al-Qahtani et al., 2014; Grinninger et al., 2015; Mohammadpour et al., 2015; Ubani-Ukoma et al., 2019). CLs are explored widely as drug carrier systems to enhance the residence time of the therapeutic molecules on the ocular surface. Various materials have been employed in fabricating CLs without effecting their oxygen permeability and light transmittance (Dubald et al., 2018; Garg et al., 2019; Wei et al., 2020). One of the major challenges in developing drug delivery systems is to optimize the relevant drug release kinetics to inhibit the microbes (Hui et al., 2014). Tan et al. (2016) reported the fabrication of drug loaded intra-ocular lens to enhance the bioavailability of the drugs. Levofloxacin solubilized in tetrahydrofuran during fabrication of intraocular lens showed sustained release of the drug compared to levofloxacin solubilized in dicholoromethane. The studies carried out using commercially available CLs displayed prolonged drug release (Karlgard et al., 2000). Hui et al. reported silicone hydrogel CLs using a molecular imprinting technique to optimize the release kinetics of ciprofloxacin. However, incorporation of ciprofloxacin during fabrication of CLs unfortunately decreased light transmission. Acrylic acid-modified CLs displayed significantly longer time for drug release than unmodified controls. In vivo studies showed that ciprofloxacin released by the modified CLs significantly inhibited $P$. aeruginosa infection than unmodified CLs (Hui et al., 2014). Kakisu et al. (2013) reported the fabrication of soft CLs for assessing their ability to uptake and release antibiotics for a better drug delivery system for treating keratitis. The prolonged release of drugs from the soft CLs was achieved by layer-by-layer (LbL) coating of polyelectrolytes (combinations of sodium alginate, chitosan, sodium hyaluronate, and poly-lysine hydrobromide) with drugs (Silva et al., 2018). LbL coating controlled the release of diclofenac sodium salt from CLs and enhanced antibacterial activity without any adverse effects. Molecular imprinting and LbL coating did not affect the properties of soft CLs, and drugs released from the lenses inhibited the growth of $S$. aureus and $S$. epidermis (Silva et al., 2021). Ciolino et al. developed econzole impregnated poly-lactic-co-glycolic acid (PLGA) and polyHEMA contact lenses for treating fungal keratitis. Econazole released from the contact lens efficiently inhibited the growth of C. albicans and displayed antifungal activity for up to three weeks. Huang et al. (2016) reported delivery of voriconazole using a hybrid CLs developed with quaternized chitosan, silver nanoparticles, and graphene oxide (HTCC/Ag/GO) for treating microbial keratitis. CLs are also used for coating with antimicrobial molecules and peptides and is one of the effective strategies for preventing or treating the microbial keratitis. Various studies have reported the coating of contact lenses with silver nanoparticles to treat microbial keratitis and showed inhibition of bacterial (Bazzaz et al., 2014; Shayani Rad et al., 2016) and fungal growth (Huang et al., 2016; Liu et al., 2018). However, the use of a high concentration of silver nanoparticles induced cytotoxicity to the mitochondrial activity, which became unsuitable for ophthalmic application (Bin Sahadan et al., 2019). Bin Sahadan et al. (2019) have reported the coating of contact lenses with phomopsidione nanoparticles, a ketone derivative, which excellently inhibited the growth of keratitis caused by Gram-negative bacteria. Melimine, a synthetic peptide derived from protamine and melittin, increased the hydrophilicity of the contact lenses and inhibited the growth of various microbes cultured on it (Dutta et al., 2013; Dutta et al., 2016a). It also inhibited P. aeruginosa-induced microbial keratitis in rabbit models (Dutta et al., 2016b). In a human trials, use of melimine-coated contact lenses increased mean corneal (depth, extent, and type) staining than control eyes (Dutta et al., 2014). Mel4, a peptide derived from melamine, also exhibited high antimicrobial activity toward $S$. aureus and $P$. aeruginosa as a contact lens coating material (Dutta et al., 2016a) and prevented the bacterial adhesion to contact lenses and displayed no sign of cytotoxicity toward rabbit models. During human trials, no sign of ocular difference was observed between test eyes (with Mel4-coated contact lenses) and the control eyes (Dutta et al., 2017).

\section{In situ Forming Hydrogels}

Hydrogels are three-dimensional polymeric networks having high water-holding capacity, which could be made from natural or synthetic hydrophilic polymer (Torres-Luna et al., 2020). They are widely used for tissue engineering and drug delivery applications as they retain the bioactive molecules within the crosslinked matrices (Lynch et al., 2020). High viscosity of the hydrogels also enhances the residence time of the bioactive molecules at ocular surface by preventing their washout. Delivery of the bioactive molecules to a local site in a controlled manner make the hydrogels a suitable drug delivery system for ocular applications. Hydrogels are usually characterized as performed gels (achieved by crosslinking the polymers) or in situ gels (Sharma and Taniguchi, 2017; Kurniawansyah et al., 2018). Formation of gels at the site of interest by changing the $\mathrm{pH}$ or temperature or ion (electrolyte) composition after reacting with surround environment make the in situ gels advantageous for enhancing the bioavailability of drugs. Various studies have reported the use of in situ hydrogels to deliver antimicrobial agents for treating corneal infection. Shastri et al. (2010) have reported the formulation of thermoreversible mucoadhesive gels using poloxamer, xanthan gum, and sodium alginate to deliver moxifloxacin hydrochloride (MXF) for corneal application. In vitro studies showed that the in situ gels were transparent, had satisfactory adhesion to the sheep's cornea, and sustained release of MXF (Shastri et al., 2010). In another study, MXF-loaded in situ hydrogels were formulated using sodium alginate and hydroxy propyl methyl cellulose (HPMC) for ocular application. In vitro studies showed the MXF released from the in situ gels inhibited bacterial growth of $E$. coli and S. aureus, whereas in vivo studies displayed that the gels were transparent and non-irritating with no ocular damage (Mandal et al., 2012). El-Laithy et al. (2011) reported the preparation of in situ gels based on Gelrite to deliver MXF for treating bacterial keratitis. MXF-loaded gels delivered higher 
amount of drug into ocular region in comparison to Vigamox ${ }^{\circledR}$ commercial eye drops without causing ocular irritation and efficiently reduced bacterial keratitis (El-Laithy et al., 2011). Nair et al. (2021) also reported the development of in situ gel formulation by optimizing the concentration of polymers like gellan gum, sodium alginate, and HPMC for enhancing bioavailability and efficiency of MXF. Selected formulation significantly improved the bioavailability of MXF to the ocular region when compared to commercially available eye (Nair et al., 2021). Mohammed et al. (2017a) reported formulation of MXF or gentamicin-loaded chitosan/ $\beta$-glycerolphosphate in situ gels for treating bacterial keratitis. Gels displayed sustained cumulative release of antibiotics that inhibited the growth of $S$. aureus and also protected the corneal fibroblast from bacteria-induced death (Mohammed et al., 2017b). Gatifloxacin was also delivered using ion-activated mucoadhesive in situ hydrogels (combination of sodium alginate, or gellan, and sodium carboxymethylcellulose) to treat bacteria keratitis in rabbit models (Kesavan et al., 2016). In vivo studies showed that ion-activated mucoadhesive hydrogels were non-irritants without causing inflammatory reactions and gatifloxacin released from the gels significantly reduced bacterial infection in comparison with marketed drug solution.

\section{Microneedle Ocular Patch}

Delivery of effective therapeutic to internal ocular regions are limited due to ocular barriers like cornea epithelium. Drugs delivered using contact lenses enhance the retention time in the ocular surface; however, penetration of drug into ocular regions is questionable. These problems are addressed using microneedle ocular patch. Microneedles ocular patch haves an array of 50-1,000 $\mu \mathrm{m}$ sized needles, which are fabricated using ceramic, metals, polymer, and silicon (Garg et al., 2019). The microneedle ocular patches containing amphotericin have also been found to be effective in treating fungal keratitis in rabbits (Roy et al., 2019). Microneedle could deliver drugs into the corneal stroma by bypassing tear films and penetrating the corneal epithelium (Lee et al., 2018). Several studies have reported the delivery of bioactive molecules or drugs using microneedle ocular patch for various applications, including keratitis. Bhatnagar et al. reported the fabrication of microneedles using polyvinyl pyrrolidone (PVP) and polyvinyl alcohol (PVA) by micromolding technique to deliver besifloxacin for treating microbial keratitis. Besifloxacin delivered into cornea by dissolution of microneedles showed enhanced antibacterial activity and reduced $S$. aureus growth in the ex vivo corneal infection model (Bhatnagar et al., 2018). In another study, Lee et al. developed a detachable hybrid microneedle pen for delivering therapeutics to treat keratitis infections. Polyhexamethylene biguanide released into the cornea from detached poly(lactic-coglycolic) acid (PLGA) microneedle showed effective inhibition of Acanthamoeba-induced keratitis in mice models (Lee et al., 2018).

\section{Nanocarriers-Based Drug Delivery}

Nanotechnology bridges a barrier between the biology and physical sciences by developing nanostructure using synthetic or natural polymers to address various problems in the field of sciences (Patra et al., 2018). Nanocarriers synthesized from biocompatible and biodegradable natural or synthetic polymers overcome corneal barriers and deliver the drug to deeper ocular regions that reduce drug toxicity and precorneal drug loss (Gote et al., 2019). Various studies have been reported regarding delivery of drugs using different nanocarriers for treating ocular disorders including keratitis. Micelles are good drug carriers that entrap the drug in the hydrophobic core; whereas, hydrophilic shells form a steric barrier and prevents micelles aggregation (Guo et al., 2020). Jaiswal et al. reported the development of micelles to deliver itraconazole for treating fungal keratitis. Itraconazole released from itraconazole-loaded micellar in situ gel showed greater antifungal activity than commercial eye drops (Jaiswal et al., 2015). Sayed et al. (2018) enhanced the penetration of itraconazole into the deeper cornea of eyes using $\beta$-cyclodextrin consolidated micellar dispersions (CCMD) to treat fungal keratitis ex vivo and in vivo models. In another study, micelles were synthesized using self-assembled poly(ethylene glycol)-block-poly(glycidyl methacrylate) (PEG-bPGMA) to deliver natamycin for treating fungal keratitis (Guo et al., 2020). Drug-loaded micelles were nontoxic, and the natamycin released from the micelles suppressed the growth of C. albicans in rabbit models. Nanoparticles are colloidal carrier systems made of natural or synthetic polymers and stores the drug in the polymer shell and deliver them to the target site (Garg et al., 2019). Ahsan et al. reported the development of anti-TLR4 antibodies-conjugated gelatin nanoparticles for enhancing the residence time of the drug ketoconazole by anchoring to the cornea. Released drug exhibited the reduction of corneal inflammation and inhibited the growth of A. flavus in rat infection models (Ahsan and Rao, 2017). Lecithin/chitosan mucoadhesive nanoparticles used or enhancing the drug retention time in ocular regions enhanced the bioavailability and resident time of amphotericin-B in the corneal region of rabbit eyes. In vitro studies displayed that amphotericin-B released from nanoparticles inhibited the growth of $C$. albicans and $A$. fumigatus more effectively than marketed formulations (Chhonker et al., 2015). Shivam et al. (2020) reported the synthesis of MXF-loaded nanoparticles entrapped in in situ gel to demonstrate sustained drug release to improve efficacy of drug in treating bacterial keratitis; reduced bacterial load and recovery of corneal epithelium was observed in in vivo studies treated with MXF-loaded nanoparticles. Nanostructured lipid nanocarriers (NLCs) are new generation formulations of solid lipid nanoparticles, which are used as an alternative for conventional drug delivery. Üstündağ-Okur et al. (2014) reported development of ofloxacin-loaded NLCs to treat bacterial keratitis. Modification of ofloxacin-loaded NLCs with chitosan enhanced the preocular residence time of the nanocarrier. Ofloxacin delivery by ofloxacin-loaded NLCschitosan showed a significantly higher rate of penetration into cornea than commercial solution. Niosome are non-ionic surfactant bilayer vesicles that are formed by the self-assembly of non-ionic surfactants in aqueous environment, also acts as a potential carrier to deliver drug for treating ocular disorders (ElNabarawi et al., 2019). They also showed natamycin-loaded 
niosomes entrapped in ketorolac tromethamine gels enhance the clinical efficacy of drug by improving its penetration of corneal tissue and minimizing inflammation associated with microbial keratitis. Natamycin delivered from the formulation inhibited the Candida albicans growth in the rabbit model and KT gels minimized the corneal inflammation caused by fungus (ElNabarawi et al., 2019). In another study, El-Mofty et al. (2020) reported the development of new formulation by modifying natamycin-loaded nanoparticle niosomal formulation along with KT to improve the safety and efficacy in fungal keratitis. Newly developed F1 (natamycin-loaded nanoparticle niosomes/ $0.5 \% \mathrm{KT}, 4 \%$ carboxymethyl cellulose gel) formulation showed higher viscosity and mucoadhesive property than $\mathrm{F} 2$ formulation (natamycin-loaded nanoparticle niosomes/0.5\% KT, $2 \%$ hydroxypropylmethyl cellulose-E4 gel). F1 formulation also enhances the penetration of drug-loaded niosomal into cornea and increased the bioavailability of the natamycin that resulted in inhibition inflammation and growth of Aspergillus spp. .

\section{CONCLUSION}

Currently, there is an alarming increase in antibiotic resistance and is considered as a global concern that requires more focused research to develop alternative therapeutic interventions to battle the growing trend. The AMR is increasing among ocular pathogens as well and impacting patient care to a large extent. The studies present in this review highlight the significant role of alternative therapeutics to combat increasing antimicrobial resistance and AMPs are explored widely and considered as the most potent new age therapeutics. The challenge has given us an opportunity to explore new antimicrobial molecules,

\section{REFERENCES}

Abd Ghafar, N., Ker-Woon, C., Hui, C. K., Mohd Yusof, Y. A., and Wan Ngah, W. Z. (2016). Acacia Honey Accelerates In Vitro Corneal Ulcer Wound Healing Model. BMC Complement. Altern. Med. 16, 259. doi:10.1186/s12906-0161248-0

Ahsan, S. M., and Rao, C. M. (2017). Condition Responsive Nanoparticles for Managing Infection and Inflammation in Keratitis. Nanoscale 9, 9946-9959. doi:10.1039/c7nr00922d

Al-Qahtani, B., Asghar, S., Al-Taweel, H. M., and Jalaluddin, I. (2014). Peripheral Ulcerative Keratitis: Our Challenging Experience. Saudi J. Ophthalmol. 28, 234-238. doi:10.1016/j.sjopt.2013.12.006

Alio, J. L., Ayala, M. J., Mulet, M. E., Artola, A., Ruiz, J. M., and Bellot, J. (1995). Antioxidant Therapy in the Treatment of Experimental Acute Corneal Inflammation. Ophthalmic Res. 27, 136-143. doi:10.1159/000267648

Anderson, B. F., Baker, H. M., Norris, G. E., Rumball, S. V., and Baker, E. N. (1990). Apolactoferrin Structure Demonstrates Ligand-Induced Conformational Change in Transferrins. Nature 344, 784-787. doi:10.1038/344784a0

Andrä, J., Berninghausen, O., and Leippe, M. (2001). Cecropins, Antibacterial Peptides from Insects and Mammals, Are Potently Fungicidal against Candida Albicans. Med. Microbiol. Immunol. 189, 169-173. doi:10.1007/s430-0018025-x

Aoki, T., Kitazawa, K., Deguchi, H., and Sotozono, C. (2021). Current Evidence for Corynebacterium on the Ocular Surface. Microorganisms 9. 254. doi:10.3390/ microorganisms 9020254

Asbell, P. A., Sahm, D. F., Shaw, M., Draghi, D. C., and Brown, N. P. (2008). Increasing Prevalence of Methicillin Resistance in Serious Ocular Infections repurpose existing molecules, explore alternative nonantibiotic therapies, and the drug delivery system that ensure concentration effective against drug-resistant pathogens. AMPs are one of the most potent alternatives that can be considered to fight antibiotic resistance as in addition to direct microbial killing activity, and it also plays an integral role in innate immune system. The small molecules targeting the virulence factors of the pathogens are also emerging as promising alternatives as they are not inhibiting microbial growth and generating selective pressure. These alternative interventions provide hope and feasible option for developing AMPs, small molecules, and natural compound analogues as future generation antimicrobials to combat antibiotic resistance.

\section{AUTHOR CONTRIBUTIONS}

SR-conceptualize the work; SR and PKJ-design of the work; PS and $\mathrm{BB}$ - figure illustrations; PKJ, PS, BB, and SR-wrote the paper.

\section{ACKNOWLEDGMENTS}

The authors sincerely acknowledge the support of the Hyderabad Eye Research Foundation. The research in the Roy laboratory was supported by grants from the Indian Council of Medical Research (5/4/6/01/Oph/2015-NCDII), DST-SERB (EMR/2016/001514), and the Department of Biotechnology (BT/PR32404/MED/30/2136/2019) and Medical Research Council, United Kingdom (Grant No. MR/S004688/1). PS received student fellowship from the University Grants Commission, Govt. of India.

Caused by Staphylococcus aureus in the United States: 2000 to 2005. J. Cataract Refract Surg. 34, 814-818. doi:10.1016/j.jcrs.2008.01.016

Augustin, D. K., Heimer, S. R., Tam, C., Li, W. Y., Le Due, J. M., Evans, D. J., et al. (2011). Role of Defensins in Corneal Epithelial Barrier Function against Pseudomonas aeruginosa Traversal. Infect. Immun. 79, 595-605. doi:10.1128/ iai.00854-10

Austin, A., Lietman, T., and Rose-Nussbaumer, J. (2017). Update on the Management of Infectious Keratitis. Ophthalmology 124, 1678-1689. doi:10.1016/j.ophtha.2017.05.012

Badenoch, P. R., Hay, G. J., Mcdonald, P. J., and Coster, D. J. (1985). A Rat Model of Bacterial Keratitis. Arch. Ophthalmol. 103, 718-722. doi:10.1001/ archopht.1985.01050050110028

Bailey, L., Gylfe, A., Sundin, C., Muschiol, S., Elofsson, M., Nordström, P., et al. (2007). Small Molecule Inhibitors of Type III Secretion inYersinia block the Chlamydia Pneumoniaeinfection Cycle. FEBS Lett. 581, 587-595. doi:10.1016/ j.febslet.2007.01.013

Ballweber, L. M., Jaynes, J. E., Stamm, W. E., and Lampe, M. F. (2002). In Vitro microbicidal Activities of Cecropin Peptides D2A21 and D4E1 and Gel Formulations Containing 0.1 to $2 \%$ D2A21 against Chlamydia trachomatis. Antimicrob. Agents Chemother. 46, 34-41. doi:10.1128/AAC.46.1.34-41.2002

Bals, R. (2000). Epithelial Antimicrobial Peptides in Host Defense against Infection. Respir. Res. 1, 141-150. doi:10.1186/rr25

Batinić-Haberle, I., Rebouças, J. S., and Spasojević, I. (2010). Superoxide Dismutase Mimics: Chemistry, Pharmacology, and Therapeutic Potential. Antioxid. Redox signaling 13, 877-918. doi:10.1089/ars.2009.2876

Baveye, S., Elass, E., Mazurier, J., Spik, G., and Legrand, D. (1999). Lactoferrin: a Multifunctional Glycoprotein Involved in the Modulation of the Inflammatory Process. Clin. Chem. Lab. Med. 37, 281-286. doi:10.1515/cclm.1999.049 
Berman, J. (2012). Candida Albicans. Curr. Biol. 22, R620-R622. doi:10.1016/ j.cub.2012.05.043

Bharathi, M. J., Ramakrishnan, R., Meenakshi, R., Padmavathy, S., Shivakumar, C., and Srinivasan, M. (2007). Microbial Keratitis in South India: Influence of Risk Factors, Climate, and Geographical Variation. Ophthalmic Epidemiol. 14, 61-69. doi:10.1080/09286580601001347

Bhatnagar, S., Saju, A., Cheerla, K. D., Gade, S. K., Garg, P., and Venuganti, V. V. K. (2018). Corneal Delivery of Besifloxacin Using Rapidly Dissolving Polymeric Microneedles. Drug Deliv. Transl. Res. 8, 473-483. doi:10.1007/s13346-0170470-8

Bin Sahadan, M. Y., Tong, W. Y., Tan, W. N., Leong, C. R., Bin Misri, M. N., Chan, M., et al. (2019). Phomopsidione Nanoparticles Coated Contact Lenses Reduce Microbial Keratitis Causing Pathogens. Exp. Eye Res. 178, 10-14. doi:10.1016/ j.exer.2018.09.011

Blair, J., Hodge, W., Al-Ghamdi, S., Balabanian, R., Lowcock, B., Pan, Y. I., et al. (2011). Comparison of Antibiotic-Only and Antibiotic-Steroid Combination Treatment in Corneal Ulcer Patients: Double-Blinded Randomized Clinical Trial. Can. J. Ophthalmol. 46, 40-45. doi:10.3129/i10-054

Bocchinfuso, G., Palleschi, A., Orioni, B., Grande, G., Formaggio, F., Toniolo, C., et al. (2009). Different Mechanisms of Action of Antimicrobial Peptides: Insights from Fluorescence Spectroscopy Experiments and Molecular Dynamics Simulations. J. Pept. Sci. 15, 550-558. doi:10.1002/psc.1144

Bohigian, G. M., and Foster, C. S. (1977). Treatment of Pseudomonas Keratitis in the Rabbit with Antibiotic-Steroid Combinations. Invest. Ophthalmol. Vis. Sci. 16, 553-556.

Boparai, J. K., and Sharma, P. K. (2020). Mini Review on Antimicrobial Peptides, Sources, Mechanism and Recent Applications. Ppl 27, 4-16. doi:10.2174/ 0929866526666190822165812

Bremond-Gignac, D., Chiambaretta, F., and Milazzo, S. (2011). A European Perspective on Topical Ophthalmic Antibiotics: Current and Evolving Options. Ophthalmol. Eye Dis. 3, S4866. doi:10.4137/oed.s4866

Buda De Cesare, G., Cristy, S. A., Garsin, D. A., and Lorenz, M. C. (2020). Antimicrobial Peptides: a New Frontier in Antifungal Therapy. mBio 11. doi:10.1128/mbio.02123-20

Burns, F. R., Paterson, C. A., Gray, R. D., and Wells, J. T. (1990). Inhibition of Pseudomonas aeruginosa Elastase and Pseudomonas Keratitis Using a Thiol-Based Peptide. Antimicrob. Agents Chemother. 34, 2065-2069. doi:10.1128/aac.34.11.2065

Butler, M. S., Blaskovich, M. A., and Cooper, M. A. (2017). Antibiotics in the Clinical Pipeline at the End of 2015. J. Antibiot. 70, 3-24. doi:10.1038/ja.2016.72

Butler, M. S., Blaskovich, M. A., and Cooper, M. A. (2013). Antibiotics in the Clinical Pipeline in 2013. J. Antibiot. 66, 571-591. doi:10.1038/ja.2013.86

Cao, Z., Said, N., Wu, H. K., Kuwabara, I., Liu, F. T., and Panjwani, N. (2003). Galectin-7 as a Potential Mediator of Corneal Epithelial Cell Migration. Arch. Ophthalmol. 121, 82-86. doi:10.1001/archopht.121.1.82

Cardoso, M. H., Meneguetti, B. T., Costa, B. O., Buccini, D. F., Oshiro, K. G. N., Preza, S. L. E., et al. (2019). Non-Lytic Antibacterial Peptides that Translocate through Bacterial Membranes to Act on Intracellular Targets. Int. J. Mol. Sci. 20, 4877. doi:10.3390/ijms20194877

Carmichael, T. R., Gelfand, Y., and Welsh, N. H. (1990). Topical Steroids in the Treatment of central and Paracentral Corneal Ulcers. Br. J. Ophthalmol. 74, 528-531. doi:10.1136/bjo.74.9.528

Cathcart, G. R. A., Quinn, D., Greer, B., Harriott, P., Lynas, J. F., Gilmore, B. F., et al. (2011). Novel Inhibitors of the Pseudomonas aeruginosa Virulence Factor LasB: a Potential Therapeutic Approach for the Attenuation of Virulence Mechanisms in Pseudomonal Infection. Antimicrob. Agents Chemother. 55, 2670-2678. doi:10.1128/aac.00776-10

Chahud, F., Ramalho, L. N. Z., Ramalho, F. S., Haddad, A., and Roque-Barreira, M. C. (2009). The Lectin KM+ Induces Corneal Epithelial Wound Healing in Rabbits. Int. J. Exp. Pathol. 90, 166-173. doi:10.1111/j.1365-2613.2008.00626.x

Chang, H. Y., and Chodosh, J. (2011). Diagnostic and Therapeutic Considerations in Fungal Keratitis. Int. Ophthalmol. Clin. 51, 33-42. doi:10.1097/ IIO.0b013e31822d64dc

Chen, H., Hua, X. M., Ze, B. C., Wang, B., and Wei, L. (2017). The Antiinflammatory Effects of Asiatic Acid in Lipopolysaccharide-Stimulated Human Corneal Epithelial Cells. Int. J. Ophthalmol. 10, 179-185. doi:10.18240/ijo.2017.02.01

Chhonker, Y. S., Prasad, Y. D., Chandasana, H., Vishvkarma, A., Mitra, K., Shukla, P. K., et al. (2015). Amphotericin-B Entrapped Lecithin/chitosan Nanoparticles for Prolonged Ocular Application. Int. J. Biol. macromolecules 72, 1451-1458. doi:10.1016/j.ijbiomac.2014.10.014

Cho, Y.-W., Yoo, W.-S., Kim, S.-J., Chung, I.-Y., Seo, S.-W., and Yoo, J.-M. (2014). Efficacy of Systemic Vitamin C Supplementation in Reducing Corneal Opacity Resulting from Infectious Keratitis. Medicine (Baltimore) 93, e125. doi:10.1097/ md.0000000000000125

Choi, S. E., and Pflum, M. K. H. (2012). The Structural Requirements of Histone Deacetylase Inhibitors: Suberoylanilide Hydroxamic Acid Analogs Modified at the C6 Position. Bioorg. Med. Chem. Lett. 22, 7084-7086. doi:10.1016/ j.bmcl.2012.09.093

Chojnacki, M., Philbrick, A., Wucher, B., Reed, J. N., Tomaras, A., Dunman, P. M., et al. (2019). Development of a Broad-Spectrum Antimicrobial Combination for the Treatment of Staphylococcus aureus and Pseudomonas aeruginosa Corneal Infections. Antimicrob. Agents Chemother. 63. e01929. doi:10.1128/ aac.01929-18

Clark, H. L., Jhingran, A., Sun, Y., Vareechon, C., De Jesus Carrion, S., Skaar, E. P., et al. (2016). Zinc and Manganese Chelation by Neutrophil S100A8/A9 (Calprotectin) Limits Extracellular Aspergillus fumigatus Hyphal Growth and Corneal Infection. J. Immunol. 196, 336-344. doi:10.4049/ jimmunol.1502037

Clark, H. L., Minns, M. S., Sun, Y., De Jesus, T., Ghannoum, M. G., and Pearlman, E. (2018). Atovaquone Impairs Growth of Aspergillus and Fusarium Keratitis Isolates by Modulating Mitochondrial Function and Zinc Homeostasis. Invest. Ophthalmol. Vis. Sci. 59, 1589-1598. doi:10.1167/iovs.17-22585

Cortes-Penfield, N., Oliver, N. T., Hunter, A., and Rodriguez-Barradas, M. (2018). Daptomycin and Combination Daptomycin-Ceftaroline as Salvage Therapy for Persistent Methicillin-Resistant Staphylococcus aureus Bacteremia. Infect. Dis. 50, 643-647. doi:10.1080/23744235.2018.1448110

Crupi, R., Impellizzeri, D., Gugliandolo, E., Cordaro, M., Siracusa, R., Britti, D., et al. (2019). Effect of Tempol, a Membrane-Permeable Free Radical Scavenger, on In Vitro Model of Eye Inflammation on Rabbit Corneal Cells. J. Ocul. Pharmacol. Ther. 35, 571-577. doi:10.1089/jop.2019.0016

Cullor, J. S., Mannis, M. J., Murphy, C. J., Smith, W. L., Selsted, M. E., and Reid, T. W. (1990). In Vitro antimicrobial Activity of Defensins against Ocular Pathogens. Arch. Ophthalmol. 108, 861-864. doi:10.1001/ archopht.1990.01070080105044

Dajcs, J. J., Hume, E. B., Moreau, J. M., Caballero, A. R., Cannon, B. M., and O'Callaghan, R. J. (2000). Lysostaphin Treatment of Methicillin-Resistant Staphylococcus aureus Keratitis in the Rabbit. Invest. Ophthalmol. Vis. Sci. 41, 1432-1437.

Dajcs, J. J., Thibodeaux, B. A., Girgis, D. O., Shaffer, M. D., Delvisco, S. M., and O'Callaghan, R. J. (2002). Immunity to Lysostaphin and its Therapeutic Value for Ocular MRSA Infections in the Rabbit. Invest. Ophthalmol. Vis. Sci. 43, 3712-3716.

Dartt, D. A. (2011). Tear Lipocalin: Structure and Function. Ocul. Surf. 9, 126-138. doi:10.1016/s1542-0124(11)70022-2

Das, S., Samantaray, R., Mallick, A., Sahu, S., and Sharma, S. (2019). Types of Organisms and In-Vitro Susceptibility of Bacterial Isolates from Patients with Microbial Keratitis: A Trend Analysis of 8 Years. Indian J. Ophthalmol. 67, 49-53. doi:10.4103/ijo.ijo_500_18

De Breij, A., Riool, M., Cordfunke, R. A., Malanovic, N., De Boer, L., Koning, R. I., et al. (2018). The Antimicrobial Peptide SAAP-148 Combats Drug-Resistant Bacteria and Biofilms. Sci. Transl Med. 10, eaan4044. doi:10.1126/ scitranslmed.aan4044

De Jong, G., Van Dijk, J. P., and Van Eijk, H. G. (1990). The Biology of Transferrin. Clinica Chim. Acta 190, 1-46. doi:10.1016/0009-8981(90)90278-Z

De Luca, A. J., and Walsh, T. J. (2000). Antifungal Peptides: Origin, Activity, and Therapeutic Potential. Rev. Iberoam Micol 17, 116-120.

Dellière, S., Sze Wah Wong, S., and Aimanianda, V. (2020). Soluble Mediators in Anti-fungal Immunity. Curr. Opin. Microbiol. 58, 24-31. doi:10.1016/ j.mib.2020.05.005

Deng, Q., Sun, M., Yang, K., Zhu, M., Chen, K., Yuan, J., et al. (2013). MRP8/14 Enhances Corneal Susceptibility toPseudomonas aeruginosaInfection by Amplifying Inflammatory Responses. Invest. Ophthalmol. Vis. Sci. 54, 1227-1234. doi:10.1167/iovs.12-10172

Di Girolamo, N. (2015). Moving Epithelia: Tracking the Fate of Mammalian Limbal Epithelial Stem Cells. Prog. Retin. Eye Res. 48, 203-225. doi:10.1016/ j.preteyeres.2015.04.002 
Djebli, N., Khier, S., Griguer, F., Coutant, A.-L., Tavernier, A., Fabre, G., et al. (2017). Ocular Drug Distribution after Topical Administration: Population Pharmacokinetic Model in Rabbits. Eur. J. Drug Metab. Pharmacokinet. 42, 59-68. doi:10.1007/s13318-016-0319-4

Do Nascimento Dias, J., De Souza Silva, C., De Araujo, A. R., Souza, J. M. T., De Holanda Veloso Junior, P. H., Cabral, W. F., et al. (2020). Mechanisms of Action of Antimicrobial Peptides ToAP2 and NDBP-5.7 against Candida Albicans Planktonic and Biofilm Cells. Sci. Rep. 10, 10327. doi:10.1038/s41598-02067041-2

Du, H., Puri, S., Mccall, A., Norris, H. L., Russo, T., and Edgerton, M. (2017). Human Salivary Protein Histatin 5 Has Potent Bactericidal Activity against ESKAPE Pathogens. Front Cel Infect Microbiol 7, 41. doi:10.3389/ fcimb.2017.00041

Dubald, M., Bourgeois, S., Andrieu, V., and Fessi, H. (2018). Ophthalmic Drug Delivery Systems for Antibiotherapy-A Review. Pharmaceutics 10, 10. doi:10.3390/pharmaceutics 10010010

Dürr, U. H. N., Sudheendra, U. S., and Ramamoorthy, A. (2006). LL-37, the Only Human Member of the Cathelicidin Family of Antimicrobial Peptides. Biochim. Biophys. Acta (Bba) - Biomembranes 1758, 1408-1425. doi:10.1016/ j.bbamem.2006.03.030

Dutta, D., Cole, N., Kumar, N., and Willcox, M. D. P. (2013). Broad Spectrum Antimicrobial Activity of Melimine Covalently Bound to Contact Lenses. Invest. Ophthalmol. Vis. Sci. 54, 175-182. doi:10.1167/iovs.12-10989

Dutta, D., Kumar, N., and D. P. Willcox, M. (2016a). Antimicrobial Activity of Four Cationic Peptides Immobilised to Poly-Hydroxyethylmethacrylate. Biofouling 32, 429-438. doi:10.1080/08927014.2015.1129533

Dutta, D., Ozkan, J., and Willcox, M. D. P. (2014). Biocompatibility of Antimicrobial Melimine Lenses. Optom. Vis. Sci. 91, 570-581. doi:10.1097/ opx.0000000000000232

Dutta, D., Vijay, A. K., Kumar, N., and Willcox, M. D. P. (2016b). Melimine-coated Antimicrobial Contact Lenses Reduce Microbial Keratitis in an Animal Model. Invest. Ophthalmol. Vis. Sci. 57, 5616-5624. doi:10.1167/iovs.16-19882

Dutta, D., Zhao, T., Cheah, K. B., Holmlund, L., and Willcox, M. D. P. (2017). Activity of a Melimine Derived Peptide Mel4 against Stenotrophomonas, Delftia, Elizabethkingia, Burkholderia and Biocompatibility as a Contact Lens Coating. Contact Lens and Anterior Eye 40, 175-183. doi:10.1016/ j.clae.2017.01.002

Edgerton, M., Koshlukova, S. E., Araujo, M. W. B., Patel, R. C., Dong, J., and Bruenn, J. A. (2000). Salivary Histatin 5 and Human Neutrophil Defensin 1 Kill Candida Albicans via Shared Pathways. Antimicrob. Agents Chemother. 44, 3310-3316. doi:10.1128/aac.44.12.3310-3316.2000

Egrilmez, S., and Yildirim-Theveny, Ş. (2020). Treatment-Resistant Bacterial Keratitis: Challenges and Solutions. Clin. Opthamol. Vol. 14, 287-297. doi:10.2147/opth.s181997

El-Laithy, H. M., Nesseem, D. I., El-Adly, A. A., and Shoukry, M. (2011). Moxifloxacin-Gelrite In Situ Ophthalmic Gelling System against Photodynamic Therapy for Treatment of Bacterial Corneal Inflammation. Arch. Pharm. Res. 34, 1663-1678. doi:10.1007/s12272-011-1011-5

El-Mofty, H. M., El-Nabarawi, M. A., Abd El Rehem, R. T., Teaima, M. H., Abary, M. Y. S., Salah, M., et al. (2020). Niosomes: Do They Increase the Potency of Topical Natamycin Ketorolac Formula in Treating Aspergillus Keratitis? an Experimental Study. J. Ocul. Pharmacol. Ther. 36, 545-554. doi:10.1089/ jop.2019.0128

El-Nabarawi, M. A., Abd El Rehem, R. T., Teaima, M., Abary, M., El-Mofty, H. M., Khafagy, M. M., et al. (2019). Natamycin Niosomes as a Promising Ocular Nanosized Delivery System with Ketorolac Tromethamine for Dual Effects for Treatment of candida Rabbit Keratitis; In Vitro/In Vivo and Histopathological Studies. Drug Dev. Ind. Pharm. 45, 922-936. doi:10.1080/ 03639045.2019.1579827

Fairbrother, R. W. (1956). Mixed Staphylococcal Infections. The Lancet 267, 716-719. doi:10.1016/s0140-6736(56)90746-2

Fanò, G., Biocca, S., Fulle, S., Mariggiò, M. A., Belia, S., and Calissano, P. (1995). The S-100: a Protein Family in Search of a Function. Prog. Neurobiol. 46, 71-82. doi:10.1016/0301-0082(94)00062-m

Farha, M. A., Czarny, T. L., Myers, C. L., Worrall, L. J., French, S., Conrady, D. G., et al. (2015). Antagonism Screen for Inhibitors of Bacterial Cell wall Biogenesis Uncovers an Inhibitor of Undecaprenyl Diphosphate Synthase. Proc. Natl. Acad. Sci. USA 112, 11048-11053. doi:10.1073/pnas.1511751112
Fazly Bazzaz, B. S., Khameneh, B., Jalili-Behabadi, M. M., Malaekeh-Nikouei, B., and Mohajeri, S. A. (2014). Preparation, Characterization and Antimicrobial Study of a Hydrogel (Soft Contact Lens) Material Impregnated with Silver Nanoparticles. Cont Lens Anterior Eye 37, 149-152. doi:10.1016/ j.clae.2013.09.008

Felise, H. B., Nguyen, H. V., Pfuetzner, R. A., Barry, K. C., Jackson, S. R., Blanc, M.P., et al. (2008). An Inhibitor of Gram-Negative Bacterial Virulence Protein Secretion. Cell Host \& Microbe 4, 325-336. doi:10.1016/j.chom.2008.08.001

Felício, M. R., Silva, O. N., Gonçalves, S., Santos, N. C., and Franco, O. L. (2017). Peptides with Dual Antimicrobial and Anticancer Activities. Front. Chem. 5, 5. doi:10.3389/fchem.2017.00005

Feng, Q., Huang, Y., Chen, M., Li, G., and Chen, Y. (2015). Functional Synergy of $\alpha$-helical Antimicrobial Peptides and Traditional Antibiotics against Gram-Negative and Gram-Positive Bacteria In Vitro and In Vivo. Eur. J. Clin. Microbiol. Infect. Dis. 34, 197-204. doi:10.1007/s10096-0142219-3

Fluckinger, M., Haas, H., Merschak, P., Glasgow, B. J., and Redl, B. (2004). Human Tear Lipocalin Exhibits Antimicrobial Activity by Scavenging Microbial Siderophores. Antimicrob. Agents Chemother. 48, 3367-3372. doi:10.1128/ aac.48.9.3367-3372.2004

Foulkes, D. M., Mclean, K., Zheng, Y., Sarsby, J., Haneef, A. S., Fernig, D. G., et al. (2021). A Pipeline to Evaluate Inhibitors of the Pseudomonas aeruginosa Exotoxin U. Biochem. J. 478, 647-668. doi:10.1042/bcj20200780

Ganz, T., and Lehrer, R. I. (1994). Defensins. Curr. Opin. Immunol. 6, 584-589. doi:10.1016/0952-7915(94)90145-7

Garg, P., Venuganti, V. V. K., Roy, A., and Roy, G. (2019). Novel Drug Delivery Methods for the Treatment of Keratitis: Moving Away from Surgical Intervention. Expert Opin. Drug Deliv. 16, 1381-1391. doi:10.1080/ 17425247.2019.1690451

Gordon, Y. J., Huang, L. C., Romanowski, E. G., Yates, K. A., Proske, R. J., and Mcdermott, A. M. (2005). Human Cathelicidin (LL-37), a Multifunctional Peptide, Is Expressed by Ocular Surface Epithelia and Has Potent Antibacterial and Antiviral Activity. Curr. Eye Res. 30, 385-394. doi:10.1080/ 02713680590934111

Gote, V., Sikder, S., Sicotte, J., and Pal, D. (2019). Ocular Drug Delivery: Present Innovations and Future Challenges. J. Pharmacol. Exp. Ther. 370, 602-624. doi:10.1124/jpet.119.256933

Grigor'eva, A., Bardasheva, A., Tupitsyna, A., Amirkhanov, N., Tikunova, N., Pyshnyi, D., et al. (2020). Changes in the Ultrastructure of Staphylococcus aureus Treated with Cationic Peptides and Chlorhexidine. Microorganisms 8. 1991. doi:10.3390/microorganisms8121991

Grinninger, P., Verbruggen, A. M. J., Kraijer-Huver, I. M. G., DjajadiningratLaanen, S. C., Teske, E., and Boevé, M. H. (2015). Use of Bandage Contact Lenses for Treatment of Spontaneous Chronic Corneal Epithelial Defects in Dogs. J. Small Anim. Pract. 56, 446-449. doi:10.1111/jsap.12360

Gritz, D. C., Kwitko, S., Trousdale, M. D., Gonzalez, V. H., and Mcdonnell, P. J. (1992). Recurrence of Microbial Keratitis Concomitant with Antiinflammatory Treatment in an Animal Model. Cornea 11, 404-408. doi:10.1097/00003226199209000-00008

Guo, Y., Karimi, F., Fu, Q., G. Qiao, G. G., and Zhang, H. (2020). Reduced Administration Frequency for the Treatment of Fungal Keratitis: a Sustained Natamycin Release from a Micellar Solution. Expert Opin. Drug Deliv. 17, 407-421. doi:10.1080/17425247.2020.1719995

Hale, J. D., and Hancock, R. E. (2007). Alternative Mechanisms of Action of Cationic Antimicrobial Peptides on Bacteria. Expert Rev. Anti-infective Ther. 5, 951-959. doi:10.1586/14787210.5.6.951

Hancock, R. E. (2000). Cationic Antimicrobial Peptides: towards Clinical Applications. Expert Opin. Investig. Drugs 9, 1723-1729. doi:10.1517/ 13543784.9.8.1723

Hancock, R. E. W., and Chapple, D. S. (1999). Peptide Antibiotics. Antimicrob. Agents Chemother. 43, 1317-1323. doi:10.1128/aac.43.6.1317

Hazlett, L. D., Ekanayaka, S. A., Mcclellan, S. A., and Francis, R. (2019). Glycyrrhizin Use for Multi-Drug Resistant Pseudomonas aeruginosa: In Vitro and In Vivo Studies. Invest. Ophthalmol. Vis. Sci. 60, 2978-2989. doi:10.1167/iovs.19-27200

Hazlett, L., Suvas, S., Mcclellan, S., and Ekanayaka, S. (2016). Challenges of Corneal Infections. Expert Rev. Ophthalmol. 11, 285-297. doi:10.1080/ 17469899.2016 .1203254 
Heidari, H., Hadadi, M., Sedigh Ebrahim-Saraie, H., Mirzaei, A., Taji, A., Hosseini, S. R., et al. (2018). Characterization of Virulence Factors, Antimicrobial Resistance Patterns and Biofilm Formation of Pseudomonas aeruginosa and Staphylococcus Spp. Strains Isolated from Corneal Infection. J. Français d'Ophtalmologie 41, 823-829. doi:10.1016/j.jfo.2018.01.012

Helmerhorst, E. J., Troxler, R. F., and Oppenheim, F. G. (2001). The Human Salivary Peptide Histatin 5 Exerts its Antifungal Activity through the Formation of Reactive Oxygen Species. Proc. Natl. Acad. Sci. 98, 14637-14642. doi:10.1073/ pnas. 141366998

Hewitt, M. G., Morrison, P. W. J., Boostrom, H. M., Morgan, S. R., Fallon, M., Lewis, P. N., et al. (2020). In Vitro Topical Delivery of Chlorhexidine to the Cornea: Enhancement Using Drug-Loaded Contact Lenses and $\beta$-Cyclodextrin Complexation, and the Importance of Simulating Tear Irrigation. Mol. Pharmaceutics 17, 1428-1441. doi:10.1021/ acs.molpharmaceut.0c00140

Hindman, H. B., Patel, S. B., and Jun, A. S. (2009). Rationale for Adjunctive Topical Corticosteroids in Bacterial Keratitis. Arch. Ophthalmol. 127, 97-102. doi:10.1001/archophthalmol.2008.504

Ho, T.-Y., Lo, H.-Y., Liu, I.-C., Lin, K.-A., Liao, Y.-F., Lo, Y.-C., et al. (2020). The Protective Effect of Quercetin on Retinal Inflammation in Mice: the Involvement of Tumor Necrosis Factor/nuclear Factor-Kb Signaling Pathways. Food Funct. 11, 8150-8160. doi:10.1039/d0fo01324b

Hoover, D. M., Rajashankar, K. R., Blumenthal, R., Puri, A., Oppenheim, J. J., Chertov, O., et al. (2000). The Structure of Human $\beta$-Defensin-2 Shows Evidence of Higher Order Oligomerization. J. Biol. Chem. 275, 32911-32918. doi:10.1074/jbc.m006098200

Hoshi, S., Todokoro, D., and Sasaki, T. (2020). Corynebacterium Species of the Conjunctiva and Nose: Dominant Species and Species-Related Differences of Antibiotic Susceptibility Profiles. Cornea 39, 1401-1406. doi:10.1097/ ico.0000000000002445

Hua, X., Yuan, X., Tang, X., Li, Z., Pflugfelder, S. C., and Li, D.-Q. (2014). Human Corneal Epithelial Cells Produce Antimicrobial Peptides LL-37 and $\beta$-Defensins in Response to Heat-Killed Candida Albicans. Ophthalmic Res. 51, 179-186. doi:10.1159/000357977

Huang, J.-F., Zhong, J., Chen, G.-P., Lin, Z.-T., Deng, Y., Liu, Y.-L., et al. (2016). A Hydrogel-Based Hybrid Theranostic Contact Lens for Fungal Keratitis. ACS nano 10, 6464-6473. doi:10.1021/acsnano.6b00601

Huang, L. C., Petkova, T. D., Reins, R. Y., Proske, R. J., and Mcdermott, A. M. (2006). Multifunctional Roles of Human Cathelicidin (LL-37) at the Ocular Surface. Invest. Ophthalmol. Vis. Sci. 47, 2369-2380. doi:10.1167/iovs.05-1649

Huang, L. C., Reins, R. Y., Gallo, R. L., and Mcdermott, A. M. (2007). CathelicidinDeficient (Cnlp-/-) Mice Show Increased Susceptibility toPseudomonas aeruginosaKeratitis. Invest. Ophthalmol. Vis. Sci. 48, 4498-4508. doi:10.1167/ iovs.07-0274

Hui, A., Willcox, M., and Jones, L. (2014). In Vitro and In Vivo Evaluation of Novel Ciprofloxacin-Releasing Silicone Hydrogel Contact Lenses. Invest. Ophthalmol. Vis. Sci. 55, 4896-4904. doi:10.1167/iovs.14-14855

Iyori, M., Kataoka, H., Shamsul, H. M., Kiura, K., Yasuda, M., Nakata, T., et al. (2008). Resveratrol Modulates Phagocytosis of Bacteria through an NF-kbdependent Gene Program. Antimicrob. Agents Chemother. 52, 121-127. doi:10.1128/aac.00210-07

Jaiswal, M., Kumar, M., and Pathak, K. (2015). Zero Order Delivery of Itraconazole via Polymeric Micelles Incorporated In Situ Ocular Gel for the Management of Fungal Keratitis. Colloids Surf. B: Biointerfaces 130, 23-30. doi:10.1016/ j.colsurfb.2015.03.059

Javia, A., Amrutiya, J., Lalani, R., Patel, V., Bhatt, P., and Misra, A. (2018). Antimicrobial Peptide Delivery: an Emerging Therapeutic for the Treatment of Burn and Wounds. Ther. Deliv. 9, 375-386. doi:10.4155/tde-2017-0061

Jensen, M. R., Bajic, G., Zhang, X., Laustsen, A. K., Koldsø, H., Skeby, K. K., et al. (2016). Structural Basis for Simvastatin Competitive Antagonism of Complement Receptor 3. J. Biol. Chem. 291, 16963-16976. doi:10.1074/ jbc.m116.732222

Ji, S., Li, Z., Song, W., Wang, Y., Liang, W., Li, K., et al. (2016). Bioactive Constituents ofGlycyrrhiza uralensis(Licorice): Discovery of the Effective Components of a Traditional Herbal Medicine. J. Nat. Prod. 79, 281-292. doi:10.1021/acs.jnatprod.5b00877

Junior, E. F. C., Guimarães, C. F. R. C., Franco, L. L., Alves, R. J., Kato, K. C., Martins, H. R., et al. (2017). Glycotriazole-peptides Derived from the Peptide
HSP1: Synergistic Effect of Triazole and Saccharide Rings on the Antifungal Activity. Amino Acids 49, 1389-1400. doi:10.1007/s00726-017-2441-2

Kakisu, K., Matsunaga, T., Kobayakawa, S., Sato, T., and Tochikubo, T. (2013). Development and Efficacy of a Drug-Releasing Soft Contact Lens. Invest. Ophthalmol. Vis. Sci. 54, 2551-2561. doi:10.1167/iovs.12-10614

Kang, H.-K., Kim, C., Seo, C. H., and Park, Y. (2017). The Therapeutic Applications of Antimicrobial Peptides (AMPs): a Patent Review. J. Microbiol. 55, 1-12. doi:10.1007/s12275-017-6452-1

Karlgard, C., Jones, L., and Moresoli, C. (2000). (Cl-176)Uptake and Release of Acular from Silicone-Hydrogel and Conventional Hydrogel Contact Lens Materials. Optom. Vis. Sci. 77, 179. doi:10.1097/00006324-200012001-00296

Kasus-Jacobi, A., Land, C. A., Stock, A. J., Washburn, J. L., and Pereira, H. A. (2020). Antimicrobial Peptides Derived from the Immune Defense Protein CAP37 Inhibit TLR4 Activation by S100A9. Invest. Ophthalmol. Vis. Sci. 61, 16. doi:10.1167/iovs.61.4.16

Kesavan, K., Kant, S., and Pandit, J. K. (2016). Therapeutic Effectiveness in the Treatment of Experimental Bacterial Keratitis with Ion-Activated Mucoadhesive Hydrogel. Ocul. Immunol. Inflamm. 24, 489-492. doi:10.3109/09273948.2015.1005238

Kessler, E., Israel, M., Landshman, N., Chechick, A., and Blumberg, S. (1982). In Vitro inhibition of Pseudomonas aeruginosa Elastase by Metal-Chelating Peptide Derivatives. Infect. Immun. 38, 716-723. doi:10.1128/iai.38.2.716723.1982

Kim, K. W., Park, S. H., Lee, S. J., and Kim, J. C. (2016). Ribonuclease 5 Facilitates Corneal Endothelial Wound Healing via Activation of PI3-kinase/Akt Pathway. Sci. Rep. 6, 31162. doi:10.1038/srep31162

Klepser, M. (2011). The Value of Amphotericin B in the Treatment of Invasive Fungal Infections. J. Crit. Care 26, 225-210. doi:10.1016/j.jcrc.2010.08.005

Klubthawee, N., Adisakwattana, P., Hanpithakpong, W., Somsri, S., and Aunpad, R. (2020). A Novel, Rationally Designed, Hybrid Antimicrobial Peptide, Inspired by Cathelicidin and Aurein, Exhibits Membrane-Active Mechanisms against Pseudomonas aeruginosa. Sci. Rep. 10, 9117. doi:10.1038/s41598-020-65688-5

Koeninger, L., Osbelt, L., Berscheid, A., Wendler, J., Berger, J., Hipp, K., et al. (2021). Curbing Gastrointestinal Infections by Defensin Fragment Modifications without Harming Commensal Microbiota. Commun. Biol. 4, 47. doi:10.1038/s42003-020-01582-0

Kolar, S. S. N., Baidouri, H., Hanlon, S., and Mcdermott, A. M. (2013). Protective Role of Murine $\beta$-Defensins 3 and 4 and Cathelin-Related Antimicrobial Peptide in Fusarium Solani Keratitis. Infect. Immun. 81, 2669-2677. doi:10.1128/iai.00179-13

Konstantinović, J., Yahiaoui, S., Alhayek, A., Haupenthal, J., Schönauer, E., Andreas, A., et al. (2020). N-Aryl-3-Mercaptosuccinimides as Antivirulence Agents Targeting Pseudomonas aeruginosa Elastase and Clostridium Collagenases. J. Med. Chem. 63, 8359-8368. doi:10.1021/ acs.jmedchem.0c00584

Korndörfer, I. P., Brueckner, F., and Skerra, A. (2007). The Crystal Structure of the Human (S100A8/S100A9)2 Heterotetramer, Calprotectin, Illustrates How Conformational Changes of Interacting a-Helices Can Determine Specific Association of Two EF-Hand Proteins. J. Mol. Biol. 370, 887-898. doi:10.1016/j.jmb.2007.04.065

Krause, A., Neitz, S., Mägert, H.-J., Schulz, A., Forssmann, W.-G., Schulz-Knappe, P., et al. (2000). LEAP-1, a Novel Highly Disulfide-Bonded Human Peptide, Exhibits Antimicrobial Activity. FEBS Lett. 480, 147-150. doi:10.1016/s00145793(00)01920-7

Kumar, A., Zhang, J., and Yu, F.-S. X. (2006). Toll-like Receptor 2-mediated Expression of $\beta$-defensin- 2 in Human Corneal Epithelial Cells. Microbes Infect. 8, 380-389. doi:10.1016/j.micinf.2005.07.006

Kurniawansyah, I., Sopyan, I., Aditya, W., Nuraini, H., Alminda, F., and Nurlatifah, A. (2018). Preformed Gel vs In Situ Gel: a Review. Int. Res. J. Pharm. 9, 1-5. doi:10.7897/2230-8407.098155

Lai, Y., and Gallo, R. L. (2009). AMPed up Immunity: How Antimicrobial Peptides Have Multiple Roles in Immune Defense. Trends Immunol. 30, 131-141. doi:10.1016/j.it.2008.12.003

Leal, S. M., Jr., Roy, S., Vareechon, C., Carrion, S., Clark, H., Lopez-Berges, M. S., et al. (2013). Targeting Iron Acquisition Blocks Infection with the Fungal Pathogens Aspergillus fumigatus and Fusarium Oxysporum. Plos Pathog. 9, e1003436. doi:10.1371/journal.ppat.1003436 
Leck, A. K., Thomas, P. A., Hagan, M., Kaliamurthy, J., Ackuaku, E., John, M., et al. (2002). Aetiology of Suppurative Corneal Ulcers in Ghana and South India, and Epidemiology of Fungal Keratitis. Br. J. Ophthalmol. 86, 1211-1215. doi:10.1136/bjo.86.11.1211

Lee, J.-E., Sun, Y., Gjorstrup, P., and Pearlman, E. (2015). Inhibition of Corneal Inflammation by the Resolvin E1. Invest. Ophthalmol. Vis. Sci. 56, 2728-2736. doi:10.1167/iovs.14-15982

Lee, K., Song, H. B., Cho, W., Kim, J. H., Kim, J. H., and Ryu, W. (2018). Intracorneal Injection of a Detachable Hybrid Microneedle for Sustained Drug Delivery. Acta Biomater. 80, 48-57. doi:10.1016/j.actbio.2018.09.039

Lee, V. T., Pukatzki, S., Sato, H., Kikawada, E., Kazimirova, A. A., Huang, J., et al. (2007). Pseudolipasin A Is a Specific Inhibitor for Phospholipase A 2 Activity of Pseudomonas aeruginosa Cytotoxin ExoU. Infect. Immun. 75, 1089-1098. doi:10.1128/iai.01184-06

Lee, W., and Lee, D. G. (2014). Lycopene-induced Hydroxyl Radical Causes Oxidative DNA Damage in Escherichia coli. J. Microbiol. Biotechnol. 24, 1232-1237. doi:10.4014/jmb.1406.06009

Lee, J. E., Lee, J., Lee, S., Kim, S., and Lee, S. (2016). The Effect of Resovin D1 on Infectious Keratitis of Experimental Animal to Prevent Corneal Scar. Invest. Ophthalmol Visual Sci. 60, 4643 .

Li, S.-A., Liu, J., Xiang, Y., Wang, Y.-J., Lee, W.-H., and Zhang, Y. (2014). Therapeutic Potential of the Antimicrobial Peptide OH-CATH30 for Antibiotic-Resistant Pseudomonas aeruginosa Keratitis. Antimicrob. Agents Chemother. 58, 3144-3150. doi:10.1128/aac.00095-14

Li, T., Li, L., Du, F., Sun, L., Shi, J., Long, M., et al. (2021). Activity and Mechanism of Action of Antifungal Peptides from Microorganisms: A Review. Molecules 26, 3438. doi:10.3390/molecules 26113438

Li, X., Yuan, M., Yin, R., Liu, X., Zhang, Y., Sun, S., et al. (2019). Histone Deacetylase Inhibitor Attenuates Experimental Fungal Keratitis in Mice. Sci. Rep. 9, 9859. doi:10.1038/s41598-019-46361-y

Li, Y., Yao, J., Han, C., Yang, J., Chaudhry, M., Wang, S., et al. (2016). Quercetin, Inflammation and Immunity. Nutrients 8, 167. doi:10.3390/nu8030167

Lim, A., Wenk, M. R., and Tong, L. (2015). Lipid-based Therapy for Ocular Surface Inflammation and Disease. Trends Molecular Medicine 21, 736-748. doi:10.1016/j.molmed.2015.10.001

Lin, A., Rhee, M. K., Akpek, E. K., Amescua, G., Farid, M., Garcia-Ferrer, F. J., et al. (2019). Bacterial Keratitis Preferred Practice PatternBacterial Keratitis Preferred Practice Pattern(R). Ophthalmology 126, P1-P55. doi:10.1016/ j.ophtha.2018.10.018

Liu, X., Chen, J., Qu, C., Bo, G., Jiang, L., Zhao, H., et al. (2018). A Mussel-Inspired Facile Method to Prepare Multilayer-AgNP-Loaded Contact Lens for Early Treatment of Bacterial and Fungal Keratitis. ACS Biomater. Sci. Eng. 4, 1568-1579. doi:10.1021/acsbiomaterials.7b00977

Luong, H. X., Thanh, T. T., and Tran, T. H. (2020). Antimicrobial Peptides Advances in Development of Therapeutic Applications. Life Sci. 260, 118407. doi:10.1016/j.lfs.2020.118407

Lynch, C. R., Kondiah, P. P., Choonara, Y. E., Du Toit, L. C., Ally, N., and Pillay, V. (2020). Hydrogel Biomaterials for Application in Ocular Drug Delivery. Front. Bioeng. Biotechnol. 8, 228. doi:10.3389/fbioe.2020.00228

Ma, L., Ye, X., Sun, P., Xu, P., Wang, L., Liu, Z., et al. (2020). Antimicrobial and Antibiofilm Activity of the EeCentrocin 1 Derived Peptide EC1-17KV via Membrane Disruption. EBioMedicine 55, 102775. doi:10.1016/ j.ebiom.2020.102775

Mallela, L. S., Sharma, P., Rao, T. S. R., and Roy, S. (2021). Recombinant IL-22 Promotes protection in a Murine Model of Aspergillus flavus Keratitis and Mediates Host Immune Responses in Human Corneal Epithelial Cells. Cell Microbiol 24, e13367. doi:10.1111/cmi.13367

Mandal, S., Prabhushankar, G., Thimmasetty, M., and Geetha, M. (2012). Formulation and Evaluation of an In Situ Gel-Forming Ophthalmic Formulation of Moxifloxacin Hydrochloride. Int. J. Pharma Investig. 2, 78-82. doi:10.4103/2230-973x.100042

Mangoni, M. L., Mcdermott, A. M., and Zasloff, M. (2016). Antimicrobial Peptides and Wound Healing: Biological and Therapeutic Considerations. Exp. Dermatol. 25, 167-173. doi:10.1111/exd.12929

Mantelli, F., and Argüeso, P. (2008). Functions of Ocular Surface Mucins in Health and Disease. Curr. Opin. Allergy Clin. Immunol. 8, 477-483. doi:10.1097/ aci.0b013e32830e6b04
Marangon, F. B., Miller, D., Muallem, M. S., Romano, A. C., and Alfonso, E. C. (2004). Ciprofloxacin and Levofloxacin Resistance Among MethicillinSensitive Staphylococcus aureus Isolates from Keratitis and Conjunctivitis. Am. J. Ophthalmol. 137, 453-458. doi:10.1016/j.ajo.2003.10.026

Marino, A., Santoro, G., Spataro, F., Lauriano, E. R., Pergolizzi, S., Cimino, F., et al. (2013). Resveratrol Role inStaphylococcus Aureus-Induced Corneal Inflammation. Pathog. Dis. 68, 61-64. doi:10.1111/2049-632x.12046

Martín Mazuelos, E., and Rodríguez-Tudela, J. L. (2008). Actividad In Vitro de anidulafungina. Comparación con la actividad de otras equinocandinas. Enfermedades Infecciosas y Microbiología Clínica 26 (Suppl. 14), 7-13. doi:10.1016/s0213-005x (08)76587-x

Matsumoto, K., Kusaka, J., Nishibori, A., and Hara, H. (2006). Lipid Domains in Bacterial Membranes. Mol. Microbiol. 61, 1110-1117. doi:10.1111/j.13652958.2006.05317.x

Matsuzaki, K., Murase, O., Fujii, N., and Miyajima, K. (1995). Translocation of a Channel-Forming Antimicrobial Peptide, Magainin 2, across Lipid Bilayers by Forming a Pore. Biochemistry 34, 6521-6526. doi:10.1021/bi00019a033

Mcdermott, A. M. (2013). Antimicrobial Compounds in Tears. Exp. Eye Res. 117, 53-61. doi:10.1016/j.exer.2013.07.014

Mcdermott, A. M., Redfern, R. L., and Zhang, B. (2001). Human SS-Defensin 2 Is Up-Regulated during Re-epithelialization of the Cornea. Curr. Eye Res. 22, 64-67. doi:10.1076/ceyr.22.1.64.6978

Mcdermott, A. M., Redfern, R. L., Zhang, B., Pei, Y., Huang, L., and Proske, R. J. (2003). Defensin Expression by the Cornea: Multiple Signalling Pathways Mediate IL-1 $\beta$ Stimulation of hBD-2 Expression by Human Corneal Epithelial Cells. Invest. Ophthalmol. Vis. Sci. 44, 1859-1865. doi:10.1167/iovs.02-0787

Mcdermott, A. M. (2009). The Role of Antimicrobial Peptides at the Ocular Surface. Ophthalmic Res. 41, 60-75. doi:10.1159/000187622

McNAMARA, N. A., Van, R., Tuchin, O. S., and Fleiszig, S. M. (1999). Ocular Surface Epithelia Express mRNA for Human Beta Defensin-2. Exp. Eye Res. 69, 483-490. doi:10.1006/exer.1999.0722

Mi, B., Liu, J., Liu, Y., Hu, L., Liu, Y., Panayi, A. C., et al. (2018). The Designer Antimicrobial Peptide A-hBD-2 Facilitates Skin Wound Healing by Stimulating Keratinocyte Migration and Proliferation. Cell Physiol Biochem 51, 647-663. doi: $10.1159 / 000495320$

Mohamed, M. F., Abdelkhalek, A., and Seleem, M. N. (2016). Evaluation of Short Synthetic Antimicrobial Peptides for Treatment of Drug-Resistant and Intracellular Staphylococcus aureus. Sci. Rep. 6, 29707. doi:10.1038/srep29707

Mohammadpour, M., Amouzegar, A., Hashemi, H., Jabbarvand, M., Kordbacheh, H., Rahimi, F., et al. (2015). Comparison of Lotrafilcon B and Balafilcon A Silicone Hydrogel Bandage Contact Lenses in Reducing Pain and Discomfort after Photorefractive Keratectomy: A Contralateral Eye Study. Contact Lens and Anterior Eye 38, 211-214. doi:10.1016/j.clae.2015.01.014

Mohammed, I., Mohanty, D., Said, D. G., Barik, M. R., Reddy, M. M., Alsaadi, A., et al. (2020). Antimicrobial Peptides in Human Corneal Tissue of Patients with Fungal Keratitis. Br. J. Ophthalmol. 105, 1172-1177. doi:10.1136/bjophthalmol-2020-316329

Mohammed, I., Said, D. G., and Dua, H. S. (2017a). Human Antimicrobial Peptides in Ocular Surface Defense. Prog. Retin. Eye Res. 61, 1-22. doi:10.1016/ j.preteyeres.2017.03.004

Mohammed, I., Said, D. G., Nubile, M., Mastropasqua, L., and Dua, H. S. (2019). Cathelicidin-Derived Synthetic Peptide Improves Therapeutic Potential of Vancomycin against Pseudomonas aeruginosa. Front. Microbiol. 10, 2190. doi:10.3389/fmicb.2019.02190

Mohammed, I., Suleman, H., Otri, A. M., Kulkarni, B. B., Chen, P., Hopkinson, A., et al. (2010). Localization and Gene Expression of Human $\beta$-Defensin 9 at the Human Ocular Surface Epithelium. Invest. Ophthalmol. Vis. Sci. 51, 4677-4682. doi:10.1167/iovs.10-5334

Mohammed, S., Chouhan, G., Anuforom, O., Cooke, M., Walsh, A., Morgan-Warren, P., et al. (2017b). Thermosensitive Hydrogel as an In Situ Gelling Antimicrobial Ocular Dressing. Mater. Sci. Eng. C 78, 203-209. doi:10.1016/j.msec.2017.04.065

Mohammad, H., Thangamani, S., and Seleem, M. (2015). Antimicrobial Peptides and Peptidomimetics - Potent Therapeutic Allies for Staphylococcal Infections. Cpd 21, 2073-2088. doi:10.2174/1381612821666150310102702

Morici, P., Fais, R., Rizzato, C., Tavanti, A., and Lupetti, A. (2016). Inhibition of Candida Albicans Biofilm Formation by the Synthetic Lactoferricin Derived Peptide hLF1-11. PloS one 11, e0167470. doi:10.1371/journal.pone.0167470 
Ming, L., and Huang, J.-A. (2017). The Antibacterial Effects of Antimicrobial Peptides OP-145 against Clinically Isolated Multi-Resistant Strains. Jpn. J. Infect. Dis. 70, 601-603. doi:10.7883/yoken.JJID.2017.090

Nagata, M., Nakamura, T., Hata, Y., Yamaguchi, S., Kaku, T., and Kinoshita, S. (2015). JBP485 Promotes Corneal Epithelial Wound Healing. Sci. Rep. 5, 14776. doi:10.1038/srep14776

Nair, A. B., Shah, J., Jacob, S., Al-Dhubiab, B. E., Sreeharsha, N., Morsy, M. A., et al. (2021). Experimental Design, Formulation and In Vivo Evaluation of a Novel Topical In Situ Gel System to Treat Ocular Infections. PloS one 16, e0248857. doi:10.1371/journal.pone.0248857

Nami, S., Aghebati-Maleki, A., Morovati, H., and Aghebati-Maleki, L. (2019). Current Antifungal Drugs and Immunotherapeutic Approaches as Promising Strategies to Treatment of Fungal Diseases. Biomed. Pharmacother. 110, 857-868. doi:10.1016/j.biopha.2018.12.009

Naranjo, A., Arboleda, A., Martinez, J. D., Durkee, H., Aguilar, M. C., Relhan, N., et al. (2019). Rose Bengal Photodynamic Antimicrobial Therapy for Patients with Progressive Infectious Keratitis: A Pilot Clinical Study. Am. J. Ophthalmol. 208, 387-396. doi:10.1016/j.ajo.2019.08.027

Ni, N., Srinivasan, M., Mcleod, S. D., Acharya, N. R., Lietman, T. M., and RoseNussbaumer, J. (2016a). Use of Adjunctive Topical Corticosteroids in Bacterial Keratitis. Curr. Opin. Ophthalmol. 27, 353-357. doi:10.1097/ icu. 0000000000000273

Ni, N., Srinivasan, M., Mcleod, S. D., Acharya, N. R., Lietman, T. M., and RoseNussbaumer, J. (2016b). Use of Adjunctive Topical Corticosteroids in Bacterial Keratitis. Curr. Opin. Ophthalmol. 27, 353-357. doi:10.1097/ icu. 0000000000000273

Nielsen, J. E., Bjørnestad, V. A., Pipich, V., Jenssen, H., and Lund, R. (2021). Beyond Structural Models for the Mode of Action: How Natural Antimicrobial Peptides Affect Lipid Transport. J. Colloid Interf. Sci. 582, 793-802. doi:10.1016/ j.jcis.2020.08.094

Nixon, G. L., Moss, D. M., Shone, A. E., Lalloo, D. G., Fisher, N., O'neill, P. M., et al. (2013). Antimalarial Pharmacology and Therapeutics of Atovaquone. J. Antimicrob. Chemother. 68, 977-985. doi:10.1093/jac/dks504

Niyonsaba, F., and Ogawa, H. (2005). Protective Roles of the Skin against Infection: Implication of Naturally Occurring Human Antimicrobial Agents $\beta$-defensins, Cathelicidin LL-37 and Lysozyme. J. Dermatol. Sci. 40, 157-168. doi:10.1016/ j.jdermsci.2005.07.009

Nordfelth, R., Kauppi, A. M., Norberg, H. A., Wolf-Watz, H., and Elofsson, M. (2005). Small-molecule Inhibitors Specifically Targeting Type III Secretion. Infect. Immun. 73, 3104-3114. doi:10.1128/iai.73.5.3104-3114.2005

Nos-Barbera, S., Portoles, M., Morilla, A., Ubach, J., Andreu, D., and Paterson, C. A. (1997). Effect of Hybrid Peptides of Cecropin A and Melittin in an Experimental Model of Bacterial Keratitis. Cornea 16, 101-106. doi:10.1097/ 00003226-199701000-00017

O'day, D. M., Head, W. S., Robinson, R. D., and Clanton, J. A. (1986). Corneal Penetration of Topical Amphotericin B and Natamycin. Curr. Eye Res. 5, 877-882. doi:10.3109/02713688609029240

Oren, Z., and Shai, Y. (1998). Mode of Action of Linear Amphipathic a-helical Antimicrobial Peptides. Biopolymers 47, 451-463. doi:10.1002/(sici)10970282(1998) 47:6<451::aid-bip4>3.0.co;2-f

Otri, A. M., Mohammed, I., Abedin, A., Cao, Z., Hopkinson, A., Panjwani, N., et al. (2010). Antimicrobial Peptides Expression by Ocular Surface Cells in Response to Acanthamoeba Castellanii: an In Vitro Study. Br. J. Ophthalmol. 94, 1523-1527. doi:10.1136/bjo.2009.178236

Paradiso, P., Serro, A. P., Saramago, B., Colaço, R., and Chauhan, A. (2016). Controlled Release of Antibiotics from Vitamin E-Loaded Silicone-Hydrogel Contact Lenses. J. Pharm. Sci. 105, 1164-1172. doi:10.1016/s0022-3549(15) 00193-8

Paredes-Gamero, E. J., Martins, M. N. C., Cappabianco, F. A. M., Ide, J. S., and Miranda, A. (2012). Characterization of Dual Effects Induced by Antimicrobial Peptides: Regulated Cell Death or Membrane Disruption. Biochim. Biophys. Acta (Bba) - Gen. Subjects 1820, 1062-1072. doi:10.1016/j.bbagen.2012.02.015

Park, J., Oh, J. H., Kang, H. K., Choi, M. C., Seo, C. H., and Park, Y. (2020). Scorpion-Venom-Derived Antimicrobial Peptide Css54 Exerts Potent Antimicrobial Activity by Disrupting Bacterial Membrane of Zoonotic Bacteria. Antibiotics (Basel) 9, 831. doi:10.3390/antibiotics9110831

Patra, J. K., Das, G., Fraceto, L. F., Campos, E. V. R., Del Pilar Rodriguez-Torres, M., Acosta-Torres, L. S., et al. (2018). Nano Based Drug Delivery Systems:
Recent Developments and Future Prospects. J. nanobiotechnology 16, 1-33. doi:10.1186/s12951-018-0392-8

Paulsen, F. P., Pufe, T., Schaudig, U., Held-Feindt, J., Lehmann, J., Schröder, J. M., et al. (2001). Detection of Natural Peptide Antibiotics in Human Nasolacrimal Ducts. Invest. Ophthalmol. Vis. Sci. 42, 2157-2163.

Pearce, J. W., Giuliano, E. A., and Moore, C. P. (2009). In Vitrosusceptibility Patterns ofAspergillusandFusariumspecies Isolated from Equine Ulcerative Keratomycosis Cases in the Midwestern and Southern United States with Inclusion of the New Antifungal Agent Voriconazole. Vet. Ophthalmol. 12, 318-324. doi:10.1111/j.1463-5224.2009.00721.x

Phan, C.-M., Subbaraman, L., and Jones, L. (2014). Contact Lenses for Antifungal Ocular Drug Delivery: a Review. Expert Opin. Drug Deliv. 11, 537-546. doi:10.1517/17425247.2014.882315

Price, M. O., and Price, F. W., Jr. (2016). Corneal Cross-Linking in the Treatment of Corneal Ulcers. Curr. Opin. Ophthalmol. 27, 250-255. doi:10.1097/ icu. 0000000000000248

Rocha, M. F. G., Sales, J. A., Da Rocha, M. G., Galdino, L. M., De Aguiar, L., PereiraNeto, W. d. A., et al. (2019). Antifungal Effects of the Flavonoids Kaempferol and Quercetin: a Possible Alternative for the Control of Fungal Biofilms. Biofouling 35, 320-328. doi:10.1080/08927014.2019.1604948

Roy, G., Galigama, R. D., Thorat, V. S., Mallela, L. S., Roy, S., Garg, P., et al. (2019). Amphotericin B Containing Microneedle Ocular Patch for Effective Treatment of Fungal Keratitis. Int. J. Pharmaceutics 572, 118808. doi:10.1016/ j.ijpharm.2019.118808

Roy, S., Marla, S., and Praneetha, D. (2015). Recognition of Corynebacterium Pseudodiphtheriticum by Toll-like Receptors and Up-Regulation of Antimicrobial Peptides in Human Corneal Epithelial Cells. Virulence 6, 716-721. doi:10.1080/21505594.2015.1066063

Ruban, V. V., Archana, P. T., Sundararajan, M., Geraldine, P., and Thomas, P. A. (2018). Inflammation and Oxidative Stress in Corneal Tissue in Experimental Keratitis Due to Fusarium Solani : Amelioration Following Topical Therapy with Voriconazole and Epigallocatechin Gallate. Mycoses 61, 159-171. doi: $10.1111 /$ myc. 12718

Rusciano, D., Pezzino, S., Olivieri, M., Cristaldi, M., Gagliano, C., Lupo, G., et al. (2018). Age-Related Dry Eye Lactoferrin and Lactobionic Acid. Ophthalmic Res. 60, 94-99. doi:10.1159/000489093

Ruszymah, B. H. I., Chowdhury, S. R., Manan, N. A. B. A., Fong, O. S., Adenan, M. I., and Saim, A. B. (2012). Aqueous Extract of Centella asiatica Promotes Corneal Epithelium Wound Healing In Vitro. J. Ethnopharmacology 140, 333-338. doi:10.1016/j.jep.2012.01.023

Sagerfors, S., Ejdervik-Lindblad, B., and Söderquist, B. (2020). Infectious Keratitis: Isolated Microbes and Their Antibiotic Susceptibility Pattern during 2004-2014 in Region Örebro County, Sweden. Acta Ophthalmol. 98, 255-260. doi:10.1111/ aos. 14256

Sayed, S., Elsayed, I., and Ismail, M. M. (2018). Optimization of $\beta$-cyclodextrin Consolidated Micellar Dispersion for Promoting the Transcorneal Permeation of a Practically Insoluble Drug. Int. J. pharmaceutics 549, 249-260. doi:10.1016/ j.ijpharm.2018.08.001

Sengupta, J., Saha, S., Khetan, A., Sarkar, S. K., and Mandal, S. M. (2012). Effects of Lactoferricin B against Keratitis-Associated Fungal Biofilms. J. Infect. Chemother. 18, 698-703. doi:10.1007/s10156-012-0398-3

Shah, D., Son, K.-N., Kalmodia, S., Lee, B.-S., Ali, M., Balasubramaniam, A., et al. (2020). Wound Healing Properties of Histatin-5 and Identification of a Functional Domain Required for Histatin-5-Induced Cell Migration. Mol. Ther. - Methods Clin. Develop. 17, 709-716. doi:10.1016/j.omtm.2020.03.027

Sharma, A., and Taniguchi, J. (2017). Review: Emerging Strategies for Antimicrobial Drug Delivery to the Ocular Surface: Implications for Infectious Keratitis. Ocul. Surf. 15, 670-679. doi:10.1016/j.jtos.2017.06.001

Sharma, P., Elofsson, M., and Roy, S. (2020). Attenuation of Pseudomonas aeruginosa Infection by INP0341, a Salicylidene Acylhydrazide, in a Murine Model of Keratitis. Virulence 11, 795-804. doi:10.1080/21505594.2020.1776979

Sharma, P., Guha, S., Garg, P., and Roy, S. (2018). Differential Expression of Antimicrobial Peptides in Corneal Infection and Regulation of Antimicrobial Peptides and Reactive Oxygen Species by Type III Secretion System of Pseudomonas aeruginosa. Pathog. Dis. 76. doi:10.1093/femspd/fty001

Sharma, P., Sharma, N., Mishra, P., Joseph, J., Mishra, D. K., Garg, P., et al. (2019). Differential Expression of Antimicrobial Peptides in Streptococcus Pneumoniae Keratitis and STAT3-dependent Expression of LL-37 by 
Streptococcus Pneumoniae in Human Corneal Epithelial Cells. Pathogens 8. 31. doi:10.3390/pathogens 8010031

Sharma, S. (2011). Antibiotic Resistance in Ocular Bacterial Pathogens. Indian J. Med. Microbiol. 29, 218-222. doi:10.4103/0255-0857.83903

Shastri, D. H., Prajapati, S. T., and Patel, L. D. (2010). Design and Development of Thermoreversible Ophthalmic In Situ Hydrogel of Moxifloxacin HCl. Curr. Drug. Deliv. 7, 238-243. doi:10.2174/156720110791560928

Shayani Rad, M., Khameneh, B., Sabeti, Z., Mohajeri, S. A., and Fazly Bazzaz, B. S. (2016). Antibacterial Activity of Silver Nanoparticle-Loaded Soft Contact Lens Materials: the Effect of Monomer Composition. Curr. Eye Res. 41, 1286-1293. doi:10.3109/02713683.2015.1123726

Shivam, U. U., Siddhi, C., Devarshi, G., Umeshkumar, M. U., and Jayvadan, K. P. (2020). Nanoparticles Laden In Situ Gel for Sustained Drug Release after Topical Ocular Administration. J. Drug Deliv. Sci. Technol. 57, 101736. doi:10.1016/j.jddst.2020.101736

Shrivastava, S., Shrivastava, P., and Ramasamy, J. (2018). Responding to the challenge of Antibiotic Resistance: World Health Organization. J. Res. Med. Sci. 23, 21. doi:10.4103/1735-1995.228593

Silva, D., De Sousa, H. C., Gil, M. H., Santos, L. F., Amaral, R. A., Saraiva, J. A., et al. (2021). Imprinted Hydrogels with LbL Coating for Dual Drug Release from Soft Contact Lenses Materials. Mater. Sci. Eng. C 120, 111687. doi:10.1016/j.msec.2020.111687

Silva, D., Sousa, H. C. d., Gil, M. H., Santos, L. F., Moutinho, G. M., Serro, A. P., et al. (2018). Antibacterial Layer-By-Layer Coatings to Control Drug Release from Soft Contact Lenses Material. Int. J. Pharmaceutics 553, 186-200. doi:10.1016/j.ijpharm.2018.10.041

Silva, N. C., Sarmento, B., and Pintado, M. (2013). The Importance of Antimicrobial Peptides and Their Potential for Therapeutic Use in Ophthalmology. Int. J. Antimicrob. Agents 41, 5-10. doi:10.1016/ j.ijantimicag.2012.07.020

Slepenkin, A., Chu, H., Elofsson, M., Keyser, P., and Peterson, E. M. (2011). Protection of Mice from a Chlamydia trachomatis Vaginal Infection Using a Salicylidene Acylhydrazide, a Potential Microbicide. J. Infect. Dis. 204, 1313-1320. doi:10.1093/infdis/jir552

Speciale, A., Chirafisi, J., Saija, A., and Cimino, F. (2011). Nutritional Antioxidants and Adaptive Cell Responses: an Update. Curr. Mol. Med. 11, 770-789. doi:10.2174/156652411798062395

Spierer, A., and Kessler, E. (1984). The Effect of 2-Mercaptoacetyl-L-PhenylalanylL-Leucine, a Specific Inhibitor of Pseudomonas aeruginosa Elastase, on Experimental Pseudomonas Keratitis in Rabbit Eyes. Curr. Eye Res. 3, 645-650. doi:10.3109/02713688409003066

Srinivasan, M., Lalitha, P., Mahalakshmi, R., Prajna, N. V., Mascarenhas, J., Chidambaram, J. D., et al. (2009). Corticosteroids for Bacterial Corneal Ulcers. Br. J. Ophthalmol. 93, 198-202. doi:10.1136/bjo.2008.147298

St. Leger, A. J., Desai, J. V., Drummond, R. A., Kugadas, A., Almaghrabi, F., Silver, P., et al. (2017). An Ocular Commensal Protects against Corneal Infection by Driving an Interleukin-17 Response from Mucosal $\gamma \delta$ T Cells. Immunity 47, 148-158. doi:10.1016/j.immuni.2017.06.014

Strahl, H., and Errington, J. (2017). Bacterial Membranes: Structure, Domains, and Function. Annu. Rev. Microbiol. 71, 519-538. doi:10.1146/annurev-micro102215-095630

Subedi, D., Vijay, A. K., and Willcox, M. (2018). Overview of Mechanisms of Antibiotic Resistance in Pseudomonas aeruginosa: an Ocular Perspective. Clin. Exp. Optom. 101, 162-171. doi:10.1111/cxo.12621

Sugar, J., and Chandler, J. W. (1974). Experimental Corneal Wound Strength. Arch. Ophthalmol. 92, 248-249. doi:10.1001/archopht.1974.01010010256018

Sun, C. C., Chiu, H. T., Lin, Y. F., Lee, K. Y., and Pang, J. H. (2015). Y-27632, a ROCK Inhibitor, Promoted Limbal Epithelial Cell Proliferation and Corneal Wound Healing. PLoS One 10, e0144571. doi:10.1371/journal.pone.0144571

Suzuki, T., Swoboda, J. G., Campbell, J., Walker, S., and Gilmore, M. S. (2011). In VitroAntimicrobial Activity of Wall Teichoic Acid Biosynthesis Inhibitors againstStaphylococcus aureusIsolates. Antimicrob. Agents Chemother. 55, 767-774. doi:10.1128/aac.00879-10

Swidergall, M., Ernst, A. M., and Ernst, J. F. (2013). Candida Albicans Mucin Msb2 Is a Broad-Range Protectant against Antimicrobial Peptides. Antimicrob. Agents Chemother. 57, 3917-3922. doi:10.1128/aac.00862-13

Tallab, R. T., and Stone, D. U. (2016). Corticosteroids as a Therapy for Bacterial Keratitis: an Evidence-Based Review of 'who, when and Why'. $B r$. J. Ophthalmol. 100, 731-735. doi:10.1136/bjophthalmol-2015-307955
Tan, D. W., Lim, S. G., Wong, T. T., and Venkatraman, S. S. (2016). Sustained Antibiotic-Eluting Intra-ocular Lenses: A New Approach. PLoS One 11, e0163857. doi:10.1371/journal.pone.0163857

Tang, W., Ma, J., Gu, R., Ding, X., Lei, B., Wang, X., et al. (2018). Lipocalin 2 Suppresses Ocular Inflammation by Inhibiting the Activation of NF-K $\beta$ Pathway in Endotoxin-Induced Uveitis. Cel Physiol Biochem 46, 375-388. doi:10.1159/000488472

Thomas, P. A. (2003). Fungal Infections of the Cornea. Eye 17, 852-862. doi:10.1038/sj.eye.6700557

Thomas, R. K., Melton, R., and Asbell, P. A. (2019). Antibiotic Resistance Among Ocular Pathogens: Current Trends from the ARMOR Surveillance Study (2009-2016). Clin. Optom. Vol. 11, 15-26. doi:10.2147/opto.s189115

Torres-Luna, C., Fan, X., Domszy, R., Hu, N., Wang, N. S., and Yang, A. (2020). Hydrogel-based Ocular Drug Delivery Systems for Hydrophobic Drugs. Eur. J. Pharm. Sci. 154, 105503. doi:10.1016/j.ejps.2020.105503

Ubani-Ukoma, U., Gibson, D., Schultz, G., Silva, B. O., and Chauhan, A. (2019). Evaluating the Potential of Drug Eluting Contact Lenses for Treatment of Bacterial Keratitis Using an Ex Vivo Corneal Model. Int. J. pharmaceutics 565, 499-508. doi:10.1016/j.jpharm.2019.05.031

Urwin, L., Okurowska, K., Crowther, G., Roy, S., Garg, P., Karunakaran, E., et al. (2020). Corneal Infection Models: Tools to Investigate the Role of Biofilms in Bacterial Keratitis. Cells 9, 2450. doi:10.3390/cells9112450

Üstündağ-Okur, N., Gökçe, E. H., Bozbıyık, D. I., Eğrilmez, S., Özer, Ö., and Ertan, G. (2014). Preparation and In Vitro-In Vivo Evaluation of Ofloxacin Loaded Ophthalmic Nano Structured Lipid Carriers Modified with Chitosan Oligosaccharide Lactate for the Treatment of Bacterial Keratitis. Eur. J. Pharm. Sci. 63, 204-215. doi:10.1016/j.ejps.2014.07.013

Van Der Weerden, N. L., Hancock, R. E. W., and Anderson, M. A. (2010). Permeabilization of Fungal Hyphae by the Plant Defensin NaD1 Occurs through a Cell wall-dependent Process. J. Biol. Chem. 285, 37513-37520. doi:10.1074/jbc.m110.134882

Van Meer, G., Voelker, D. R., and Feigenson, G. W. (2008). Membrane Lipids: where They Are and How They Behave. Nat. Rev. Mol. Cel Biol 9, 112-124. doi:10.1038/nrm2330

Wang, G. (2008). Structures of Human Host Defense Cathelicidin LL-37 and its Smallest Antimicrobial Peptide KR-12 in Lipid Micelles. J. Biol. Chem. 283, 32637-32643. doi:10.1074/jbc.m805533200

Wang, N. N., Yan, X., Gao, X. N., Niu, H. J., Kang, Z. S., and Huang, L. L. (2016). Purification and Characterization of a Potential Antifungal Protein from Bacillus Subtilis E1R-J against Valsa mali. World J. Microbiol. Biotechnol. 32, 63. doi:10.1007/s11274-016-2024-5

Wei, Y., Hu, Y., Shen, X., Zhang, X., Guan, J., and Mao, S. (2020). Design of Circular-Ring Film Embedded Contact Lens for Improved Compatibility and Sustained Ocular Drug Delivery. Eur. J. Pharmaceutics Biopharmaceutics 157, 28-37. doi:10.1016/j.ejpb.2020.09.010

Whitcher, J. P., Srinivasan, M., and Upadhyay, M. P. (2001). Corneal Blindness: a Global Perspective. Bull. World Health Organ. 79, 214-221.

Wilcox, C. S. (2010). Effects of Tempol and Redox-Cycling Nitroxides in Models of Oxidative Stress. Pharmacol. Ther. 126, 119-145. doi:10.1016/ j.pharmthera.2010.01.003

Wiig, M., Olmarker, K., Håkansson, J., Ekström, L., Nilsson, E., and Mahlapuu, M. (2011). A Lactoferrin-Derived Peptide (PXL01) for the Reduction of Adhesion Formation in Flexor Tendon Surgery: an Experimental Study in Rabbits. J. Hand Surg. Eur. Vol. 36, 656-662. doi:10.1177/1753193411410823

Wilkinson, A., Kawaguchi, N., Geczy, C., and Di Girolamo, N. (2016). S100A8 and S100A9 Proteins Are Expressed by Human Corneal Stromal Dendritic Cells. Br. J. Ophthalmol. 100, 1304-1308. doi:10.1136/bjophthalmol-2016308827

Willcox, M. D. P. (2011). Review of Resistance of Ocular Isolates of Pseudomonas aeruginosa and Staphylococci from Keratitis to Ciprofloxacin, Gentamicin and Cephalosporins. Clin. Exp. Optom. 94, 161-168. doi:10.1111/j.14440938.2010.00536.x

Wu, L., Ye, M., and Zhang, J. (2018). Vincamine Prevents Lipopolysaccharide Induced Inflammation and Oxidative Stress via Thioredoxin Reductase Activation in Human Corneal Epithelial Cells. Am. J. Transl Res. 10, 2195-2204.

Wu, M., Mcclellan, S. A., Barrett, R. P., Zhang, Y., and Hazlett, L. D. (2009). B-Defensins 2 and 3 Together Promote Resistance toPseudomonas aeruginosaKeratitis. J. Immunol. 183, 8054-8060. doi:10.4049/jimmunol.0902140 
Yan, H., Wang, Y., Shen, S., Wu, Z., and Wan, P. (2017). Corticosteroids Effects on LPS-Induced Rat Inflammatory Keratocyte Cell Model. PloS one 12, e0176639. doi:10.1371/journal.pone.0176639

Yin, J., Peng, X., Lin, J., Zhang, Y., Zhang, J., Gao, H., et al. (2021). Quercetin amelioratesAspergillus Fumigatuskeratitis by Inhibiting Fungal Growth, Tolllike Receptors and Inflammatory Cytokines. Int. Immunopharmacology 93, 107435. doi:10.1016/j.intimp.2021.107435

Yin, J., and Yu, F.-S. X. (2010). LL-37 via EGFR Transactivation to Promote High Glucose-Attenuated Epithelial Wound Healing in Organ-Cultured Corneas. Invest. Ophthalmol. Vis. Sci. 51, 1891-1897. doi:10.1167/iovs.093904

Zeth, K., and Sancho-Vaello, E. (2017). The Human Antimicrobial Peptides Dermcidin and LL-37 Show Novel Distinct Pathways in Membrane Interactions. Front. Chem. 5, 86. doi:10.3389/fchem.2017.00086

Zhao, G., Li, S., Zhao, W., He, K., Xi, H., Li, W., et al. (2012). Phage Display against Corneal Epithelial Cells Produced Bioactive Peptides that Inhibit Aspergillus Adhesion to the Corneas. PLoS One 7, e33578. doi:10.1371/ journal.pone.0033578

Zhu, Y., Peng, X., Zhang, Y., Lin, J., and Zhao, G. (2021). Baicalein Protects against Aspergillus fumigatus Keratitis by Reducing Fungal Load and Inhibiting TSLP-
Induced Inflammatory Response. Invest. Ophthalmol. Vis. Sci. 62, 26. doi:10.1167/iovs.62.6.26

Conflict of Interest: The authors declare that the research was conducted in the absence of any commercial or financial relationships that could be construed as a potential conflict of interest.

Publisher's Note: All claims expressed in this article are solely those of the authors and do not necessarily represent those of their affiliated organizations, or those of the publisher, the editors and the reviewers. Any product that may be evaluated in this article, or claim that may be made by its manufacturer, is not guaranteed or endorsed by the publisher.

Copyright (C) 2021 Jadi, Sharma, Bhogapurapu and Roy. This is an open-access article distributed under the terms of the Creative Commons Attribution License (CC $B Y)$. The use, distribution or reproduction in other forums is permitted, provided the original author(s) and the copyright owner(s) are credited and that the original publication in this journal is cited, in accordance with accepted academic practice. No use, distribution or reproduction is permitted which does not comply with these terms. 